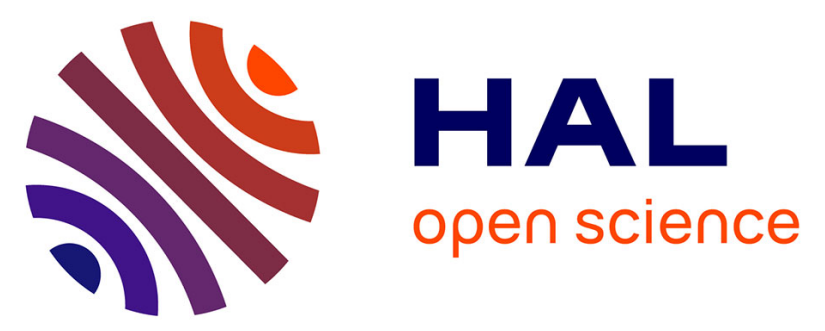

\title{
Practical Assessment of Anionic Redox in Li-Rich Layered Oxide Cathodes: A Mixed Blessing for High Energy Li-Ion Batteries
}

Gaurav Assat, Charles Delacourt, Daniel Alves Dalla Corte, Jean-marie Tarascon

\section{To cite this version:}

Gaurav Assat, Charles Delacourt, Daniel Alves Dalla Corte, Jean-marie Tarascon. Practical Assessment of Anionic Redox in Li-Rich Layered Oxide Cathodes: A Mixed Blessing for High Energy Li-Ion Batteries. Journal of The Electrochemical Society, 2016, 163 (14), pp.A2965-A2976. $10.1149 / 2.0531614$ jes . hal-01489447

\section{HAL Id: hal-01489447 https://hal.sorbonne-universite.fr/hal-01489447}

Submitted on 14 Mar 2017

HAL is a multi-disciplinary open access archive for the deposit and dissemination of scientific research documents, whether they are published or not. The documents may come from teaching and research institutions in France or abroad, or from public or private research centers.
L'archive ouverte pluridisciplinaire HAL, est destinée au dépôt et à la diffusion de documents scientifiques de niveau recherche, publiés ou non, émanant des établissements d'enseignement et de recherche français ou étrangers, des laboratoires publics ou privés.

\section{(c)(1)}

Distributed under a Creative Commons Attribution| 4.0 International License 


\title{
Practical Assessment of Anionic Redox in Li-Rich Layered Oxide Cathodes: A Mixed Blessing for High Energy Li-Ion Batteries
}

\author{
Gaurav Assat, ${ }^{a, b, c}$ Charles Delacourt, ${ }^{\text {,,d,* }}$ Daniel Alves Dalla Corte, ${ }^{a, b}$ \\ and Jean-Marie Tarascon ${ }^{\mathrm{a}, \mathrm{b}, \mathrm{c}, \mathrm{z}}$ \\ ${ }^{a}$ Collège de France - Chimie du Solide et de l'Energie, 75005 Paris, France \\ ${ }^{b}$ Réseau sur le Stockage Electrochimique de l'Energie (RS2E), FR CNRS 3459, 80039 Amiens Cedex, France \\ ${ }^{c}$ UPMC Univ Paris 06, Sorbonne Universités, 75005 Paris, France \\ ${ }^{d}$ Laboratoire de Réactivité et Chimie des Solides (LRCS), UMR CNRS 7314, Université de Picardie Jules Verne, \\ 80039 Amiens Cedex, France
}

\begin{abstract}
Li-rich layered oxides, e.g. $\mathrm{Li}\left[\mathrm{Li}_{0.20} \mathrm{Ni}_{0.13} \mathrm{Mn}_{0.54} \mathrm{Co}_{0.13}\right] \mathrm{O}_{2}$ (LR-NMC), lead high energy density Li-ion battery cathodes, thanks to the reversible redox of oxygen anions that boost charge storage capacity. Unfortunately, their commercialization has been stalled by practical issues (i.e. voltage hysteresis, poor rate capability, and voltage fade) and hence it is necessary to investigate whether these problems are intrinsically inherent to anionic redox and its structural consequences. To this end, the 'model' Li-rich layered oxide $\mathrm{Li}_{2} \mathrm{Ru}_{0.75} \mathrm{Sn}_{0.25} \mathrm{O}_{3}$ (LRSO) is here used as a fertile test-bed for scrutinizing the effects of cationic and anionic redox independently since they are neatly isolated at low and high potentials, respectively. Through an arsenal of electrochemical techniques, we demonstrate that voltage hysteresis is triggered by anionic redox and grows progressively with deeper oxidation of oxygen in conjunction with the deterioration of both interfacial charge-transfer kinetics and bulk diffusion coefficient. We equally show that this anionic-driven poor kinetics keeps deteriorating further with cycling and we also find that voltage fades faster if oxygen is kept oxidized for longer. Our findings, which are in fact harsher for LR-NMC, convey caution that anionic redox risks practical problems; hence, when chasing larger capacities with this class of materials, we encourage considering real-world applications.

(C) The Author(s) 2016. Published by ECS. This is an open access article distributed under the terms of the Creative Commons Attribution Non-Commercial No Derivatives 4.0 License (CC BY-NC-ND, http://creativecommons.org/licenses/by-nc-nd/4.0/), which permits non-commercial reuse, distribution, and reproduction in any medium, provided the original work is not changed in any way and is properly cited. For permission for commercial reuse, please email: oa@electrochem.org. [DOI: 10.1149/2.0531614jes] All rights reserved.

(cc) BY-NC-ND
\end{abstract}

Manuscript submitted September 12, 2016; revised manuscript received October 21, 2016. Published November 4, 2016.

Improving energy density is one of the core goals for materials scientists in the field of rechargeable batteries. For Li-ion batteries based on intercalation hosts, energy density is limited by the charge storage capacity of the positive electrode material. ${ }^{1,2}$ Despite extensive efforts leading to brilliant discoveries of positive electrode classes such as $\mathrm{LiCoO}_{2}$-type layered oxides, $\mathrm{LiMn}_{2} \mathrm{O}_{4}$-type spinel oxides, and poly-anionic compositions such as $\mathrm{LiFePO}_{4}$-type olivine phosphates, their practical capacity could not exceed $200 \mathrm{mAh} . \mathrm{g}^{-1}$. This is because they rely solely on cationic redox couples of their $3 d$ transition metals (TM) which are either simply limited in quantity (in case of spinels and poly-anions), or they cannot be practically utilized fully due to the instability of the host lattice (in case of layered). Today's leading commercial batteries utilize $\mathrm{LiMO}_{2}$-type, nickel-based layered oxides such as $\mathrm{Li}\left[\mathrm{Ni}_{1-\mathrm{x}-\mathrm{y}} \mathrm{Mn}_{\mathrm{x}} \mathrm{Co}_{\mathrm{y}}\right] \mathrm{O}_{2}(\mathrm{NMC})$ and $\mathrm{Li}\left[\mathrm{Ni}_{0.80} \mathrm{Co}_{0.15} \mathrm{Al}_{0.05}\right] \mathrm{O}_{2}$ (NCA), but their electronic structures discourage complete oxidation of TMs due to stability and safety concerns, hence limiting the upper cutoff voltage and in turn the practical capacity too. ${ }^{3}$ A significant breakthrough was the design of Li-rich layered oxides, e.g. $\mathrm{Li}\left[\mathrm{Li}_{0.20} \mathrm{Ni}_{0.13} \mathrm{Mn}_{0.54} \mathrm{Co}_{0.13}\right] \mathrm{O}_{2}$ (LR-NMC), which surpassed this capacity limit by virtue of the reversible redox of $\mathrm{O}^{2-}$ anions in addition to cationic redox, as recently demonstrated with both experiments and theory. ${ }^{4-7}$

LR-NMCs, often expressed as (1-x). $\mathrm{Li}_{2} \mathrm{MnO}_{3}-x \cdot \mathrm{LiMO}_{2}$ with (M $=\mathrm{Ni}, \mathrm{Mn}$, and $\mathrm{Co}$ ) either in a solid solution or as a nano-composite, exhibit reversible capacities reaching $280 \mathrm{mAh}_{\mathrm{g}} \mathrm{g}^{-1}$ (and > $300 \mathrm{mAh} . \mathrm{g}^{-1}$ at $\left.55^{\circ} \mathrm{C}\right),{ }^{8}$ values that cannot be explained by cationic redox alone. ${ }^{5}$ This extra capacity originates from anionic redox, as validated recently by Density Functional Theory (DFT) calculations ${ }^{9}$ and direct experimental proofs with soft X-ray absorption spectroscopy (XAS) ${ }^{10,11}$ and X-ray photoelectron spectroscopy. ${ }^{12,13}$ Despite the promise of large capacities, unfortunately, a decade long research effort in commercializing LR-NMCs has remained unsuccessful because the extra capacity comes with undesirable practical drawbacks, such as voltage fade, voltage hysteresis, and poor rate capability. ${ }^{14-16}$ Firstly, irreversible voltage fade diminishes energy density upon cycling and

*Electrochemical Society Member.

${ }^{\mathrm{z}}$ E-mail: jean-marie.tarascon@ college-de-france.fr makes state-of-charge (SOC) management difficult. Secondly, voltage hysteresis also complicates SOC management and in addition, penalizes round trip energy efficiency, ${ }^{17}$ just like in conversion materials which unfortunately failed to commercialize despite decades of theoretical and experimental research due to the unsolved hysteresis problem. ${ }^{18-21}$ And thirdly, poor rate capability reduces power density and energy efficiency to generate extra heat.

Strategies for mitigation of these issues must target their fundamental origins, which are difficult to determine using LR-NMC since it is complicated by interweaved electrochemical activity of three TMs and oxygen. It is widely believed that the anionic redox in LR$\mathrm{NMC}$, as well as its deficiencies listed above, mainly originates from its $\mathrm{Li}$ and $\mathrm{Mn}$-rich nature, leaning toward $\mathrm{Li}_{2} \mathrm{MnO}_{3}$, which can also be expressed as $\mathrm{Li}\left[\mathrm{Li}_{1 / 3} \mathrm{Mn}_{2 / 3}\right] \mathrm{O}_{2}$, a notation that elucidates the layered structure having excess $\mathrm{Li}$ in the Mn layers. Direct evidence for oxygen redox participation in $\mathrm{Li}_{2} \mathrm{MnO}_{3}$ was recently proven experimentally with soft XAS. ${ }^{22,23}$ Spectroscopic evidence of sluggish reaction kinetics for de-lithiation associated with $\mathrm{Mn}$ sites ${ }^{24}$ in LR-NMC corroborates the electrochemically observed kinetic limitations ${ }^{25}$ at potentials where its $\mathrm{Li}_{2} \mathrm{MnO}_{3}$ component is believed to be active. Besides, according to Argonne's research reports, the issues of hysteresis and voltage fade are correlated and have also been attributed to arise from the $\mathrm{Li}_{2} \mathrm{MnO}_{3}$ 'domains'. ${ }^{26}$

Aware of the aforementioned complexity of LR-NMC and the key role of its $\mathrm{Li}_{2} \mathrm{MnO}_{3}$ component, our group designed simplified (or 'model') Li-rich layered oxides based on solid solutions of $\mathrm{Li}_{2} \mathrm{M}^{4+} \mathrm{O}_{3}(\mathrm{M}=\mathrm{Mn}, \mathrm{Ru}, \mathrm{Sn}$, and $\mathrm{Ti})$, which also can be written as $\mathrm{Li}\left[\mathrm{Li}_{1 / 3} \mathrm{M}_{2 / 3}\right] \mathrm{O}_{2}$. The electrochemical parallel between LR-NMC and our 'model' oxides is embodied in a characteristic two-step first charge followed by an 'S-shaped'-sloped discharge. This resemblance has roots in the structural and chemical similarities between them. By partially substituting $\mathrm{Mn}$ with $\mathrm{Ru}$ in $\mathrm{Li}_{2} \mathrm{MnO}_{3}$, clear evidence was obtained for both cationic redox (from $\mathrm{Ru}^{4+/ 5+}$ ) and anionic redox (from $\left.\left(\mathrm{O}_{2}\right)^{4-/ \mathrm{n}-}\right) .^{27}$ Later, by switching from $\mathrm{Mn}^{4+}$ to electrochemically inactive $\mathrm{Sn}^{4+}\left(d^{10}\right)$, the undesirable $\mathrm{Mn}^{3+/ 4+}$ redox was also eliminated, leaving behind a simplified system with just two main redox active elements, i.e. Ru and O. ${ }^{4}$ By leveraging this simplified system, we can now investigate the role of anionic redox in triggering 
practical issues such as voltage fade, hysteresis, and poor kinetics. This is important because anionic redox is the key physiochemical phenomenon in these materials such that once the electrons are removed from the O- $2 p$ levels, it can lead to unstable 'O-holes' that may cause structural reorganizations (as confirmed with DFT $^{6,7,28}$ ) such as $\mathrm{O}_{2}$ release, O-O pairing and/or TM migrations, which may be only partially reversible depending on the chemical and electronic structure. For the sake of clarity, we use the term 'anionic redox' in this paper to discuss the effects of the complete process of Li-transfer with electron exchange from the $\mathrm{O}$ bands that may consequently also lead to significant structural reorganizations.

In this study, the optimized composition of $\mathrm{Li}_{2} \mathrm{Ru}_{0.75} \mathrm{Sn}_{0.25} \mathrm{O}_{3}$ (LRSO) serves as a 'model' material. It reversibly delivers a high capacity in excess of $240 \mathrm{mAh} . \mathrm{g}^{-1}$, thanks to a combination of cationic and anionic redox that are neatly separated at low and high potentials respectively, thus enabling their individual scrutiny. ${ }^{29}$ Furthermore, large-sized spectator cations of $\mathrm{Sn}^{4+}$ preserve structural integrity upon cycling and hence reduce cycling-induced voltage fade. ${ }^{28}$ Although the higher cost of Ru might confine LRSO to niche applications such as space or defense, our main objective with this material is to develop fundamental understandings for the class of Li-rich layered oxides in general. We thus embarked into a detailed electrochemical study of LRSO to explore its thermodynamic, kinetic and transport properties in a step by step manner, starting from the first charge 'activation' process, then continuing with 'activated' LRSO which is applicationwise important, and finally ending with the cycling induced voltage fade and impedance buildup. In the next sections, we first present our results on LRSO and then follow up with a detailed discussion comparing the two Li-rich layered oxides - LRSO (the 'model' system with $4 d$ TM) and LR-NMC (the 'practical' system with $3 d$ TMs). Many striking similarities are revealed between the two, despite moving from $3 d$ to $4 d$ TMs, providing key fundamental insights toward practical challenges that affect anionic redox and Li-rich layered oxides.

\section{Experimental}

Material synthesis and electrode fabrication.-Single-phase $\mathrm{Li}_{2} \mathrm{Ru}_{0.75} \mathrm{Sn}_{0.25} \mathrm{O}_{3}$ (LRSO) samples, as determined by X-ray powder diffraction (XRD) (BRUKER D8 Advance diffractometer with $\mathrm{Cu}$ $\mathrm{K} \alpha$ radiation, $\lambda_{\mathrm{K} \alpha 1}=1.54056 \AA, \lambda_{\mathrm{K} \alpha 2}=1.54439 \AA$ ), are prepared by solid-state synthesis, as reported previously. ${ }^{4}$ The powders consist of 'potato-shaped' particles having an average size ranging from 1 to 3 $\mu \mathrm{m}$, as deduced by Scanning Electron Microscopy (SEM) (Hitachi S$3400 N$ ) (Supp. Info. Figure S1). Electrochemical testing is performed with electrodes made by Bellcore's plastic method. ${ }^{30} \mathrm{~A}$ blend of active material and Carbon Super P (CSP), mixed first in a SPEX 8000 M ball-miller for 15 minutes, is stirred overnight in dry acetone with a binder - Poly(vinylidene fluoride-co-hexafluoropropylene) (PVDFHFP), and a plasticizer - dibutylphthalate (DBP). After casting this slurry on a smooth surface, a self-standing electrode can be peeled off once the acetone evaporates. DBP is then extracted by rinsing the film thoroughly with diethyl ether, which leaves behind a large porosity. The final electrode film is composed of $73 \%$ (by weight) active material, $9 \% \mathrm{CSP}$, and $18 \%$ binder with an active material loading of $\sim 5 \mathrm{mg} . \mathrm{cm}^{-2}, \sim 50 \mu \mathrm{m}$ film-thickness, and $\sim 60 \%$ porosity. Such an electrode design is essential for safely ignoring porous-electrode effects; low loading and high porosity ensure that the electrode's electrochemical response is dominated by the sought-after properties of the active material. Circular disks of $\sim 1 \mathrm{~cm}^{2}$ geometric area are used in each cell.

Electrochemical measurement protocols.-Two-electrode electrochemical measurements are carried out in coin-cell-type batteries with Li metal foil as the counter electrode whereas three-electrode measurements are performed with Swagelok-type batteries also having Li metal foil as the counter electrode and a small piece of Li metal as the reference electrode, fixed at the exposed tip of an otherwise enameled thin copper wire (180 $\mu \mathrm{m}$ diameter). The cells are assembled in an argon-filled glove-box with a Whatman GF/D borosilicate glass fiber sheet as the separator soaked with an electrolyte - LP100 (Merck) having $1 \mathrm{M} \mathrm{LiPF}_{6}$ in ethylene carbonate: propylene carbonate: dimethyl carbonate in a 1:1:3 weight ratio. All cells are rested overnight before testing. Depending on the experiment, measurements are either performed with a constant current (CC) or a constant current constant voltage $(\mathrm{CCCV})$ protocol. The $\mathrm{CCCV}$ protocol holds the voltage at the end of the $\mathrm{CC}$ step until the current decays to a predefined small value, such as $\mathrm{C} / 100$ (unless otherwise specified). In this work, $1 \mathrm{C}$ corresponds to $160 \mathrm{~mA} \cdot \mathrm{g}^{-1}$ based on $1 \mathrm{Li}$ exchanged from LRSO in one hour. Activation of LRSO requires five formation cycles with a CCCV protocol within $2-4.6 \mathrm{~V}$ vs. $\mathrm{Li} / \mathrm{Li}^{+}$.

Electroanalytical techniques and their description.-Galvanostatic intermittent titration technique (GITT), Potentiostatic intermittent titration technique (PITT), and Electrochemical Impedance Spectroscopy (EIS) are used to quantify the near-equilibrium voltage profiles, the interfacial charge-transfer resistance, and the bulk diffusion coefficient by using a simplified model assuming spherical particles. At short time after switching on the current pulse, the GITT solution of the Fick's diffusion equation predicts a linear relationship between the cell potential and the square root of time ${ }^{31,32}$ from which the diffusion coefficient can be determined. In this work, we use the short time PITT solutions of Fick's diffusion equation in a spherical geometry that also incorporate the boundary condition of finite interfacial kinetics, ${ }^{33,34}$ which therefore are more accurate compared to the original solution for planar geometry, ${ }^{31}$ where infinitely fast surface reaction is assumed. This PITT model is based on two parameters that quantify, respectively, the surface reaction resistance and the bulk diffusion coefficient. For EIS, a GITT type of protocol is followed to allow the material to rest and equilibrate at a desired SOC before measuring impedance with a $10 \mathrm{mV}$ wave having frequencies varying from $200 \mathrm{kHz}$ to $1.4 \mathrm{mHz}$. With EIS, the Fickian diffusion coefficient is calculated from the Warburg resistance at low frequencies where the imaginary and real parts of impedance show linearity with $f^{-0.5}$, where $f$ is the frequency. ${ }^{35,36}$ Throughout this work, we report the values of $D / R^{2}\left[\mathrm{~s}^{-1}\right]$ as deduced directly from the experiments, where $D$ is the diffusion coefficient and $R$ is the particle radius. $D / R^{2}$ represents the reciprocal of the time constant associated with the Li diffusion process and hence it is a physically meaningful quantity. We do not calculate $D$ by multiplying with $R^{2}$, in order to avoid the error associated with estimating $R$ from SEM images.

\section{Results}

'Staircase-like' first-charge - first step at 3.6 V.-The typical voltage vs. composition trace of a Li half-cell, having either LR-NMC or LRSO as the positive electrode, shows a stair-case voltage profile on oxidation that is modified into an 'S-shaped' one on reduction (Figure 1a). Moreover, note the superimposition of the voltage profiles for four consecutively assembled LRSO cells that indicates the robustness of our experiments. The first $3.6 \mathrm{~V}$ redox process corresponding to the de-insertion of $0.75 \mathrm{Li}$ per formula unit (theoretical as well as practical capacity of $120 \mathrm{mAh} \cdot \mathrm{g}^{-1}$ ), is known to be purely associated to the oxidation of $0.75 \mathrm{Ru}^{4+}$ to $\mathrm{Ru}^{5+} .4,29$ We evaluate the reversibility of this process vs. $\mathrm{Li} / \mathrm{Li}^{+}$with GITT. Figure 1a-inset shows a good matching of open-circuit voltages (OCVs) between charge and discharge along with almost complete recovery of capacity that indicates excellent reversibility. Furthermore, cycling over the first redox step is fairly stable (Figure 1b). This is evidenced by the derivative capacity $(d Q / d V)$ graph showing a double peak that is mirrored between charge and discharge and that neatly superimposes between the $3^{\text {rd }}$ and $22^{\text {nd }}$ cycles with a small capacity loss, thus indicating the absence of any irreversible voltage fade. Overall, the abovementioned results demonstrate that LRSO behaves alike a classical intercalation mechanism when cycling in this range of Li stoichiometry.

To interrogate LRSO's kinetic and transport properties during the first redox step, i.e. respectively, the charge-transfer resistance and diffusion coefficient, we use complementary electrochemical techniques, namely PITT and EIS in addition to the aforementioned GITT. The 
Number of $\mathrm{Li}^{+}$exchanged
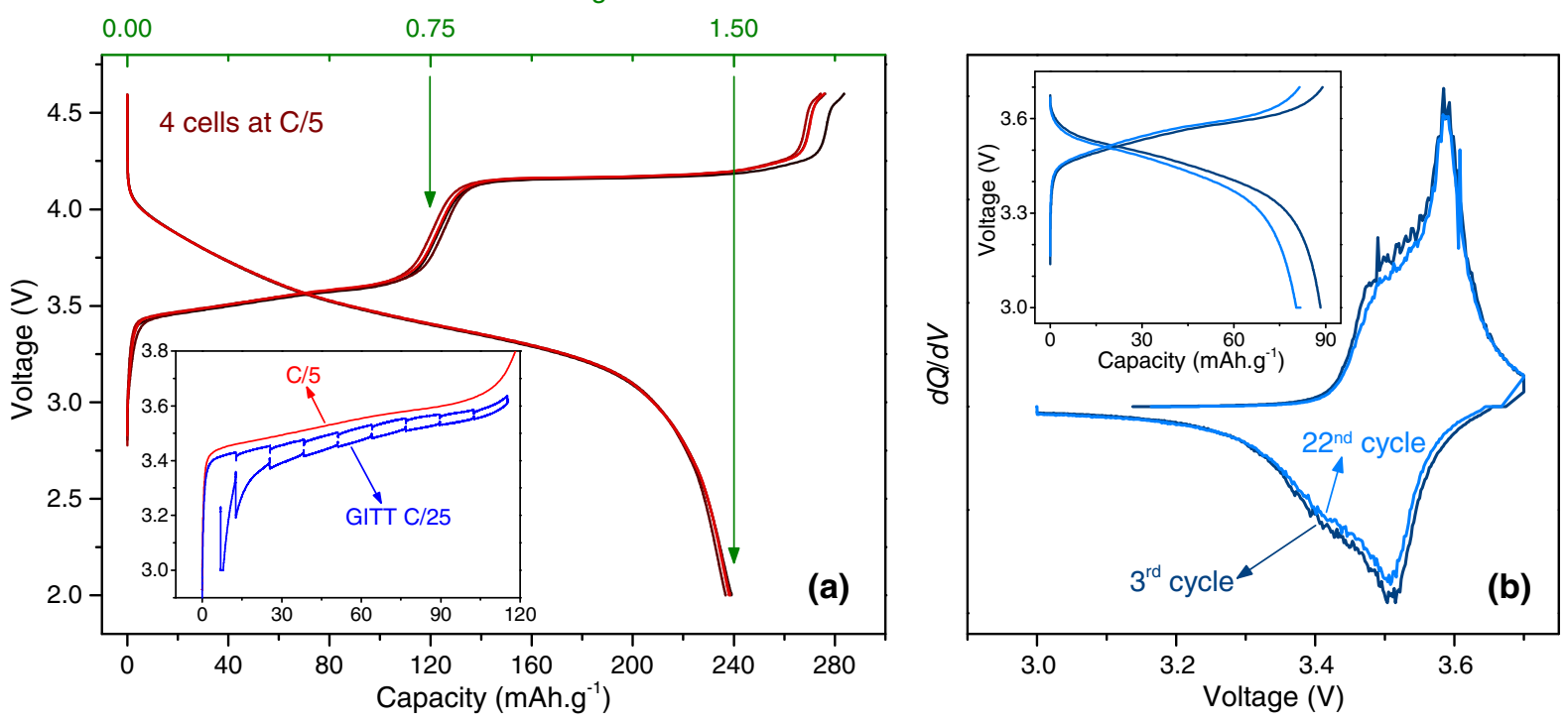

Figure 1. (a) Typical voltage profile during LRSO's first cycle (CC protocol at C/5) changes from 'staircase' charge to S-shaped' discharge. Four identical cells show excellent repeatability. Inset shows GITT voltage profiles $(2 \mathrm{hr}$. C/25 pulse, $4 \mathrm{hr}$. rest) that match closely in OCV between charge and discharge. (b) $d Q / d V$ curves for restricted cycling only over the $3.6 \mathrm{~V}$ redox step with their corresponding voltage profiles in the inset.

variation of Li diffusion coefficient with SOC, measured using GITT, is presented in Figure S2a (Supp. Info.). A linear variation of $V$ vs. $t^{0.5}$, as theoretically expected at short time after switching on the current pulse, is exemplified in Figure S2b (Supp. Info.). Note that $D / R^{2}$, which refers to the time constant associated with solid-state diffusion of $\mathrm{Li}$ in the bulk, varies from $8 \times 10^{-6}$ to $2 \times 10^{-5} \mathrm{~s}^{-1}$ throughout a sizeable part of the first redox step on first charge.

EIS measurements are collected in a three-electrode cell at varying SOCs over charge and discharge that correspond to the OCVs in the EIS-GITT curve (Figure 2a). As an example, the Nyquist plot for Point 1 on charge is shown in Figure $2 \mathrm{~b}$ and it can be subdivided broadly into three frequency domains. The depressed semicircle at high frequencies (HF) in the $1000-100 \mathrm{~Hz}$ range is ascribed to a combination of fast electrochemical processes, such as interface contact with the current collector, electronic conductivity, inter-particle contact or thin solid electrolyte interface (SEI) layer. Next, the charge-transfer resistance $\left(R_{c t}\right)$ at the electrode/electrolyte interface and the double layer charging/discharging are responsible for a semicircular feature at medium frequencies $(\mathrm{MF})$ in the range of $10-0.1 \mathrm{~Hz}$. Finally, at low frequencies $(\mathrm{LF})<0.1 \mathrm{~Hz}$, a $45^{\circ}$ straight line in the Nyquist plot denotes the Warburg impedance related to solid-state diffusion of $\mathrm{Li}$ in the bulk. ${ }^{37-39}$ Based on this description, an equivalent circuit model (Fig. 2b-top) provides excellent fits of the experimental data.

The evolution of EIS spectra over the first redox step can be followed in Figure S3 (Supp. Info.) where it is evident that the HF arc does not change much with SOC. Secondly, the MF feature related to $R_{c t}$ remains small throughout the process, barely discernable from the Warburg tail. On the other hand, the most noticeable changes occur in the LF domain, related to Li diffusion. Fitting the EIS spectra with the equivalent circuit model (Figure $2 \mathrm{~b}$-top) provides parameters for calculation of $D / R^{2}$. As seen in Figure $2 \mathrm{a}, D / R^{2}$ varies from $2 \times$ $10^{-5}$ to $5 \times 10^{-5} \mathrm{~s}^{-1}$, similar to the results from GITT (Fig. S2a). Lastly, the $D / R^{2}$ and interfacial resistance terms are also deduced from PITT by fitting the experimental data (Fig. S4 of Supp. Info.) using the two-parameter single-particle model having spherical geometry, as described in the Experimental section. PITT confirms (Figure 2c) the trends deduced from both EIS and GITT measurements. Moreover, PITT also enables us to deduce the diffusion coefficients at this step's very beginning/end, where voltage changes steeply with $\mathrm{Li}$ content. Fig. $2 \mathrm{~d}$ shows the complete variation of $D / R^{2}$ vs. $V$, having two minima that neatly correspond with the two $d Q / d V$ (right axis) peaks. Such a correlation between $D / R^{2}$ and $d Q / d V$ again characterizes a typical intercalation mechanism, also known for graphite ${ }^{40,41}$ and spinel- $\mathrm{LiMn}_{2} \mathrm{O}_{4}{ }^{42}$ that has theoretical origins in non-idealities expressed by a thermodynamic factor for activity correction. ${ }^{43,44}$

'Staircase-like' first-charge - second step at 4.15 V plateau.-We now turn to the exploration of the thermodynamic and kinetic properties at LRSO's high voltage plateau $(4.15 \mathrm{~V})$. The GITT voltage profile, collected through the whole first charge (Figure 3a), reveals a striking difference between the two staircase steps, namely in terms of the time to reach OCV, which is only of a few hours for the first $3.6 \mathrm{~V}$ step (Fig. 3a inset), in agreement with the above-mentioned results. In contrast, the OCV vs. time curves (Fig. 3a inset) at the $4.15 \mathrm{~V}$ plateau show a never-ending voltage relaxation even for rest periods close to 2 days, hence indicating a process having a large time constant. Remarkably, Figure $3 \mathrm{~b}$ shows that upon very slow charging (i.e. $\mathrm{CC}$ at $\mathrm{C} / 100$ and PITT with $\mathrm{C} / 500$ cutoff), the under-current potential traces cling to the $4.15 \mathrm{~V}$ plateau instead of the significantly lower potentials seen during open-circuit conditions. Also, only a weak increase of polarization despite increasing the current by a factor of $20(\mathrm{C} / 100$ to $\mathrm{C} / 5)$, implies that the plateau has fast charge-transfer kinetics. However, the fundamental origin of slow relaxation under open-circuit condition is unclear and it may be related to the sluggish equilibration and hence mixed potential ${ }^{45}$ between pristine and 'activated' LRSO, resembling conversion-type materials in this regard. In summary, the removal of $\mathrm{Li}$ from LRSO at the $4.15 \mathrm{~V}$ plateau, that accompanies anionic redox, triggers an irreversible, electrochemically-driven phase transformation (or 'activation'), which turns out to have fast charge-transfer kinetics but slow equilibration dynamics. Transformed or 'activated' LRSO exhibits a permanently modified electrochemistry, expressed in subsequent cycling as 'S-shaped'-sloped charge and discharge profiles.

Post-activation - hysteresis and path dependence.-Fundamental exploration of the first cycle is essential, but when considering realworld applications, it is important to know how the cell behaves after reaching its transformed state. It takes around five cycles with a CCCV protocol (at $\mathrm{C} / 5$ with $\mathrm{C} / 100$ cutoff) or ten cycles with a $\mathrm{CC}$ protocol (at C/5) within 2-4.6 V for LRSO to achieve a fairly stable voltage profile on charge and discharge. Post-activation, GITT findings in Figure 4 a show a significant voltage gap $(\sim 100 \mathrm{mV})$ between OCVs 

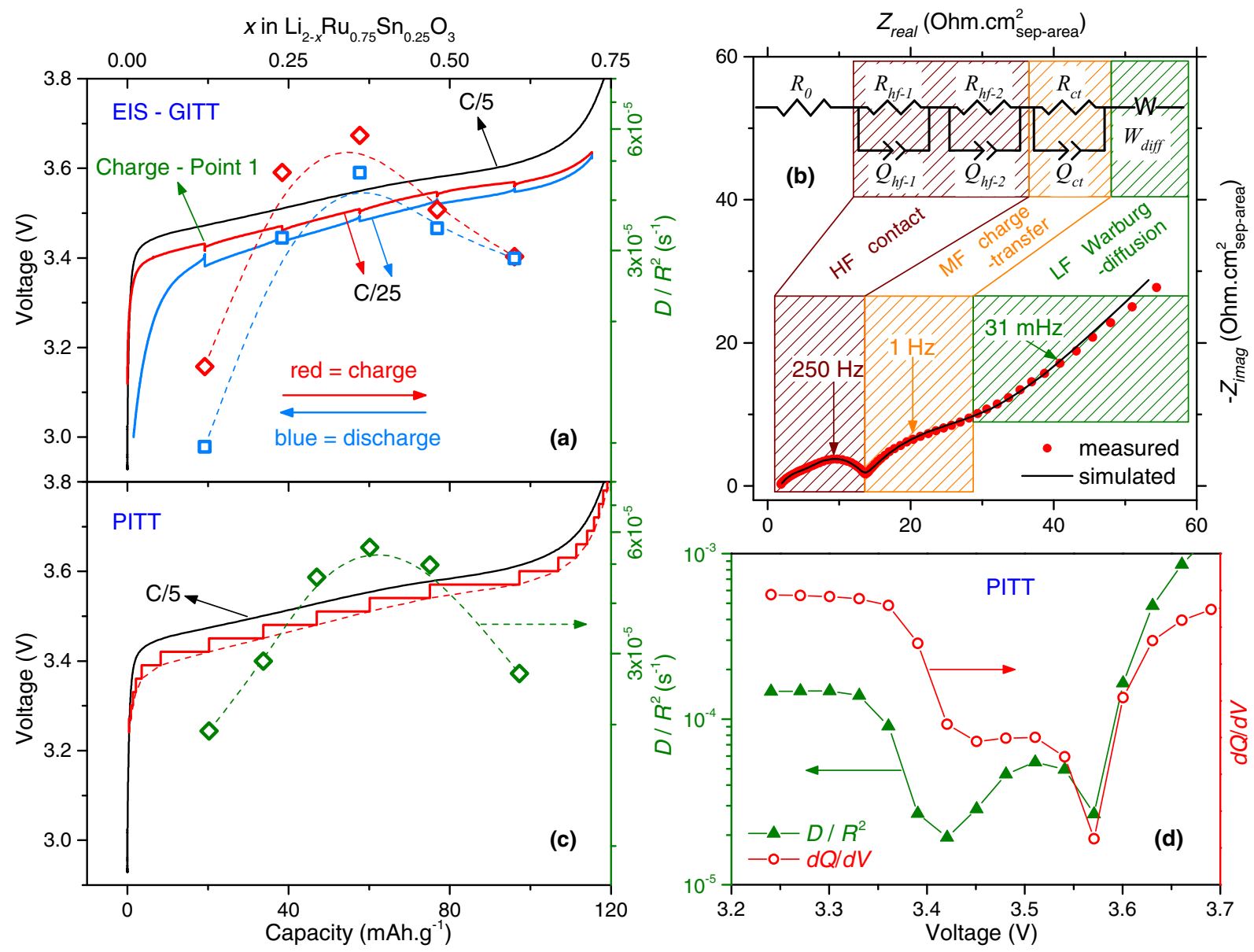

Figure 2. (a) EIS - GITT voltage profiles (left axis) ( $3 \mathrm{hr}$. C/25 pulse, $4 \mathrm{hr}$. rest) and corresponding diffusion time constants, $D / R^{2}$ (right axis). (b) Example EIS Nyquist spectrum measured at point 1 on charge along with the simulated spectrum based on the equivalent circuit model shown at the top. (c) PITT voltage profile (30 mV step, C/500 cutoff) and corresponding values for $D / R^{2}$. (d) Variation of $D / R^{2}$ vs. potential measured with PITT, showing its correlation with the $d Q / d V$ profile (right axis).

at charge vs. discharge despite very long rest periods of 24 hours. In classical intercalation materials, the OCVs match at a particular SOC between charge and discharge, however in our case, very slow equilibration dynamics (beyond $24 \mathrm{hrs}$.) prevail. Therefore, GITT indicates thermodynamic hysteresis in activated LRSO and this is further confirmed with complementary experiments of cycling at a small C-rate of C/50 (Fig. S5 Supp. Info.) to minimize kinetic effects. Again, a 150-250 mV voltage gap remains despite small currents indicating that it is not arising from kinetic limitations but is rather related to hysteresis, such that the path followed during de-lithiation is different from the one taken on lithiation.

Next, we explore what causes the onset of this hysteresis through electrochemical techniques and particularly, we identify the role of anionic redox. 'Activated'-LRSO is cycled by charging alternatively with $\mathrm{CC}$ or $\mathrm{CCCV}$ protocols, switching back and forth between them with increasing cycles. The resulting discharge voltage profiles and $d Q / d V$ traces are shown in Figure $4 \mathrm{~b}$. A total capacity of nearly 240 mAh.g ${ }^{-1}$ is delivered; out of which about half accounts theoretically for the oxidation of $0.75 \mathrm{Ru}^{4+}$, indicating almost equal capacity contributions from the cationic redox of $\mathrm{Ru}^{4+/ 5+}$ and the anionic redox of $\left(\mathrm{O}_{2}\right)^{4-/ \mathrm{n}-}$. These two processes on discharge can respectively be assigned to the $d Q / d V$ peaks centered around $3.3 \mathrm{~V}$ and $3.7 \mathrm{~V}^{29} \mathrm{In}$ short, the first half of the 'S-shaped'-sloped profile at lower voltages primarily involves cationic redox and after crossing the mid-point (or $50 \%$ SOC), oxygen is the major redox species at higher voltages. A deeper charge with CCCV (implying more oxygen oxidation) leads to an expected additional discharge capacity (more intense $3.7 \mathrm{~V} d Q / d V$ peak) that is however shifted down to a slightly lower discharge voltage, which is counterintuitive (Fig. 4b). This unanticipated drop in the entire voltage profile upon full activation of anionic redox with $\mathrm{CCCV}$ is not permanent because the voltage jumps back up if the next cycle is charged with CC only. Therefore, it cannot be assigned to irreversible formation of a passivation SEI layer during the hold at $4.6 \mathrm{~V}$ and we hypothesize that anionic redox either leads to poorer kinetics/transport properties and/or it causes a reversible thermodynamic hysteresis. To test this claim, further experiments are conducted.

Figure 5a shows the effect of cycling 'activated'-LRSO by progressively increasing the charge cutoff voltage with each cycle but always followed by a discharge to $2 \mathrm{~V}$ after a 2 hour OCV period in between. In each cycle, starting from the fully discharged state, LRSO follows the same charge profile as one would expect. However, discharge voltage profiles steadily fall along with a simultaneous growth of polarization over-potential (right axis), after the de-lithiation level crosses the half way mark, i.e. $50 \%$ SOC. These effects are particularly severe after passing $3.6 \mathrm{~V}$, above which is primarily the anionic redox region. The discharge profile of $50 \%$ charged LRSO is compared against $100 \%$ charged LRSO and the latter shows a larger overall polarization (about $200 \mathrm{mV}$ at $50 \%$ SOC), which can alternatively be visualized in the $d Q / d V$ curves (Figure 5a- inset) as a voltage profile collapse, thereby pointing to a hysteresis that is triggered upon full charging. In a complementary experiment, shown in Figure 5b, LRSO is cycled with a similar protocol but this time by gradually opening the discharge voltage window. It can be inferred that a discharge of at least more than $50 \%$ SOC is necessary to begin the recovery 


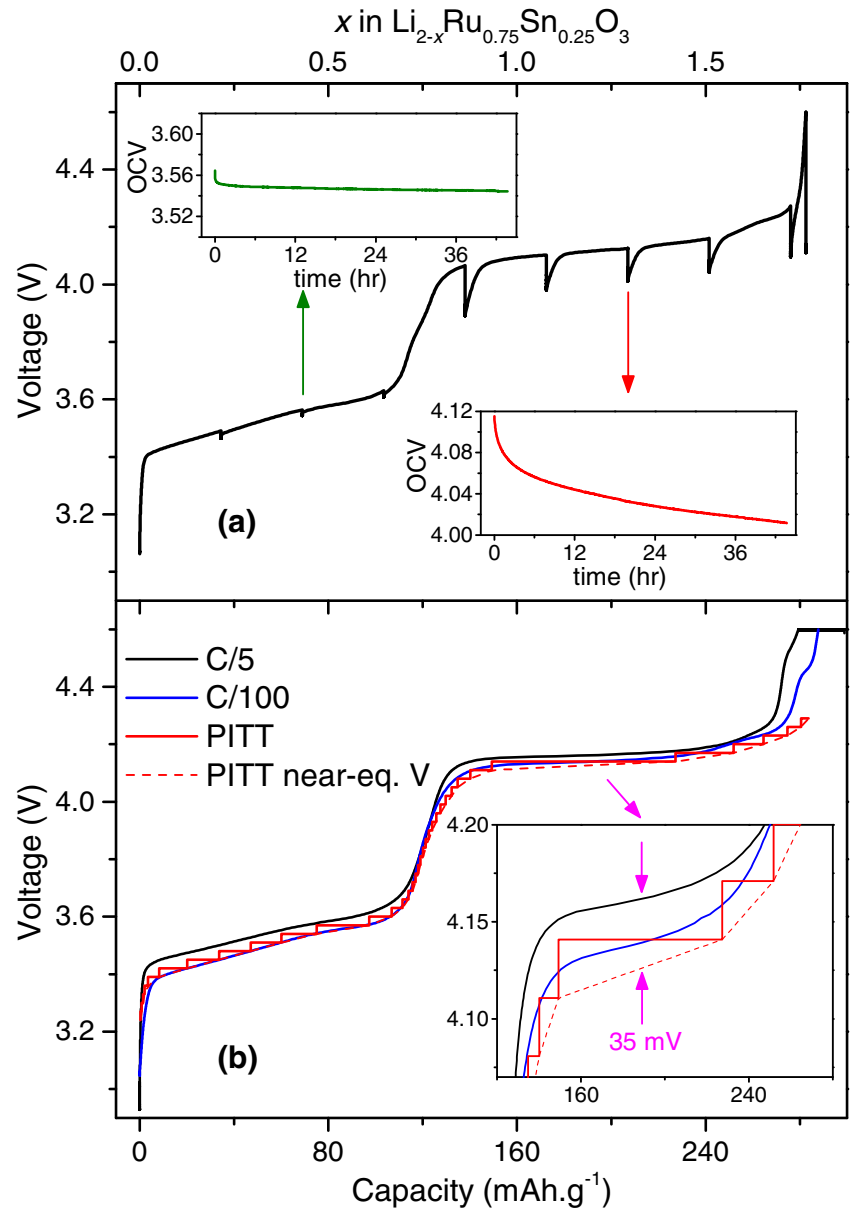

Figure 3. (a) Long-rest GITT voltage profile ( $4 \mathrm{hr}$. C/20 pulse, $44 \mathrm{hr}$. rest) over the whole first-charge with the insets showing contrasting behavior at the two staircase steps in terms of OCV vs. time curves. (b) Comparison of first-charge voltage profiles at $\mathrm{C} / 5, \mathrm{C} / 100$, and PITT (30 $\mathrm{mV}$ step, C/500 cutoff) with the inset showing a small polarization over-potential at the $4.15 \mathrm{~V}$ plateau.

of dropped voltage profiles (Fig. 5b-inset). This shows that charge paths are dependent on discharge histories (also vice versa), and not just SOC, therefore this path dependence has thermodynamic origins. Lastly, polarization over-potentials (right axis) which represent electrochemical resistance are found to recuperate in a reverse fashion during the first half of discharge. In summary, this pair of experiments confirms our hypothesis that activating anionic redox not only causes a reversible thermodynamic hysteresis (or path dependence) but also triggers kinetic limitations (over-potentials), which are investigated next in greater detail.

Post-activation - kinetics and transport properties.-A part of the voltage polarization seen above, is attributable to slow interfacial kinetics and/or bulk diffusion, and when operating at practical current values, these limitations can impact energy efficiency and also limit the attainable charge/discharge capacity. We thus begin to explore the kinetic and transport properties of 'activated'-LRSO with the help various electroanalytical techniques such as EIS, GITT, and PITT, applied to well-designed electrodes that permit the use of simplified models for reliable quantification of the desired properties. Qualified electrodes must have low active-material loading and high porosity (specifications in Experimental section) to minimize undesired porous-electrode effects and counter electrode polarization and thus ensure that the intrinsic properties of LRSO govern the results.

Rate capability.-Once the Li / LRSO cells are activated, they are tested with a CCCV charge and discharge protocol involving step by step increments in current (or C-rate) with each cycle, scanning from a very slow $\mathrm{C} / 50$ to a more practical value of $1 \mathrm{C}$. Figure 6a shows the resulting voltage profiles and Figure $6 \mathrm{~b}$ shows the corresponding $d Q / d V$ curves. During charge, polarizations do not show up until the last stages of de-lithiation, demonstrating excellent rate capability for charging of LRSO throughout the cationic redox regime but suggests limitations at higher potential, where at higher currents, we see an earlier termination of capacity with correspondingly diminishing $d Q / d V$ profiles above $3.7 \mathrm{~V}$. This contrasts with the discharge voltage profiles that are more polarized in the beginning at the higher potential peak. Most evidently, the $d Q / d V$ profiles (Fig. 6b) show a striking movement of the oxygen reduction peaks upon increasing the current from $\mathrm{C} / 50$ to $1 \mathrm{C}$ in comparison to the $\mathrm{Ru}^{4+15+}$ peaks that are virtually anchored at $3.3 \mathrm{~V}$ at all C-rates. Because the cell in this experiment ages with every cycle, we performed two consecutive cycles each at $\mathrm{C} / 2.5$ and $1 \mathrm{C}$, which virtually superimpose to validate that ageing-related voltage fade and impedance buildup cause a much smaller voltage drop $\left(\Delta V_{\text {ageing }}\right)$ compared to the kinetic polarization induced by current increment $\left(i R_{\text {kinetic }}\right)$, i.e. $\Delta V_{\text {ageing }} \ll i R_{\text {kinetic }}$ (Figure 6a-inset). In an analogous supporting test, we scanned the discharge response to increasing currents for 'activated'-LRSO, which is this time charged only to $3.9 \mathrm{~V}$ at $\mathrm{C} / 5$ (just cationic redox therefore) for every discharge C-rate. The $d Q / d V$ peak is anchored again at $3.3 \mathrm{~V}$ in Figure S6 (Supp. Info.), hence reinforcing faster discharge kinetics of cationic redox while the higher potential peak related to oxygen redox is not triggered. These experiments clearly point to kinetic and transport resistances for anionic redox in comparison to the much faster
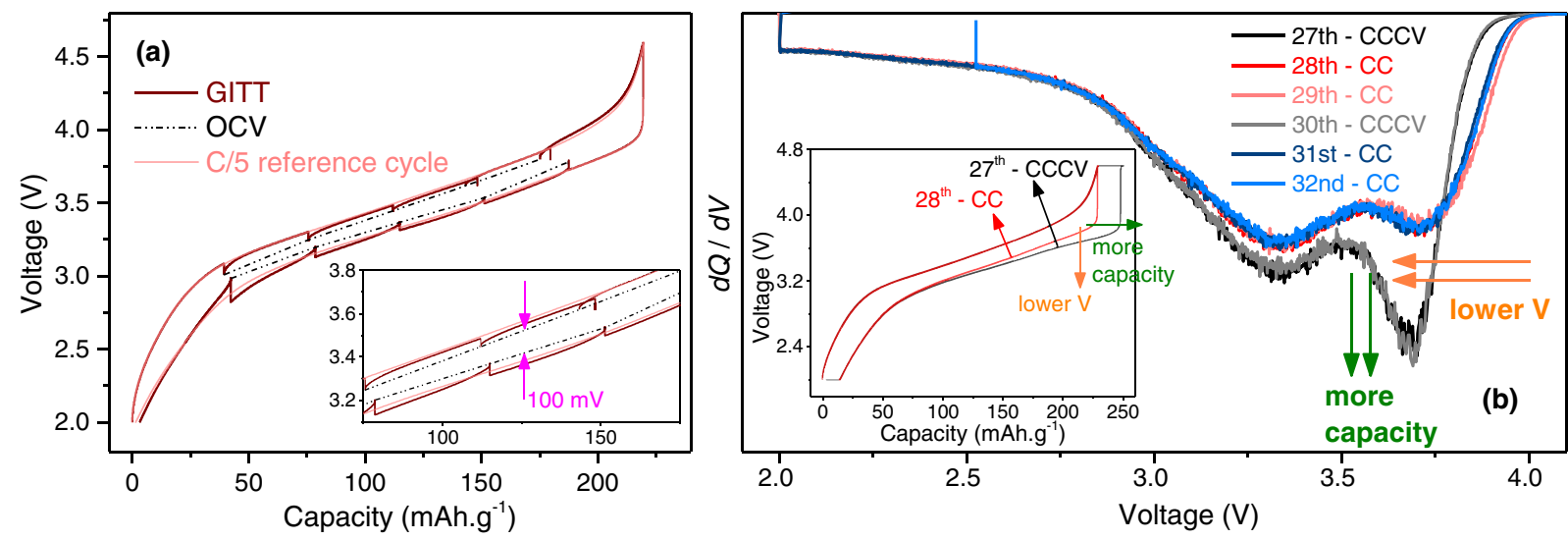

Figure 4. (a) GITT voltage profile $(\mathrm{C} / 5,24 \mathrm{hr}$. rest) with magnification in the inset showing significant thermodynamic hysteresis $(\sim 100 \mathrm{mV})$ despite very long OCV periods. (b) Discharge $d Q / d V$ profiles and corresponding voltage traces (inset) for cycling at $\mathrm{C} / 5$ alternatively with CC or CCCV charge protocols. CCCV charge at $4.6 \mathrm{~V}$ fully oxidizes anions to produce extra discharge capacity (green arrow) however at slightly lower potentials (orange arrow). 


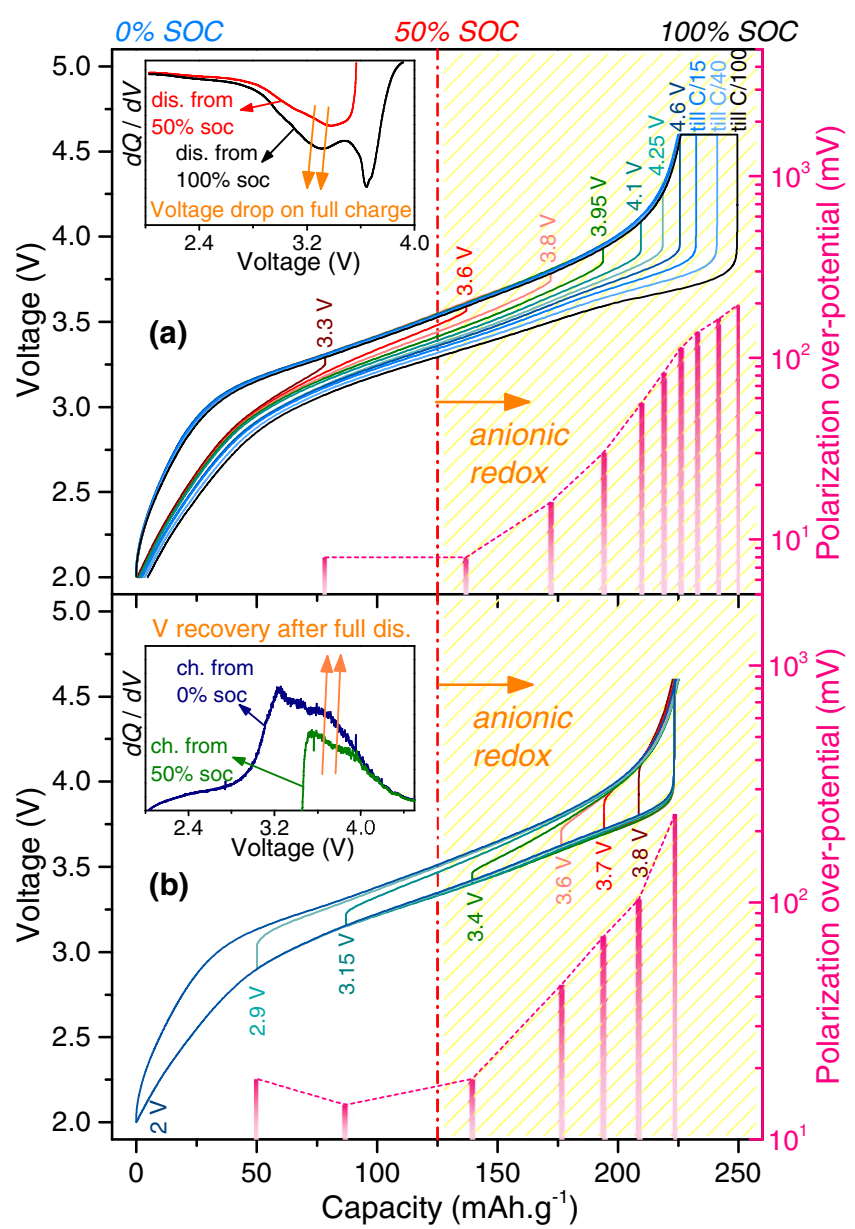

Figure 5. Effect of voltage window on hysteresis (insets) and polarization over-potentials (right axis) in 'activated'-LRSO. (a) The charge window is progressively opened with each cycle by increasing the upper cutoff voltage. Charge profiles are identical but discharge profiles drop gradually upon activating anionic redox after 50\% SOC with simultaneous rapid growth of over-potential (right axis). The inset compares discharge $d Q / d V$ profiles of $50 \%$ and $100 \%$ charged LRSO with the latter displaying more capacity but a dropped potential. (b) A complementary experiment of opening the discharge window with each cycle such that all discharges are identical but the charge profiles start to regain higher potentials only after complete anionic reduction (inset). Over-potentials (right axis) also decrease back with anionic reduction. The inset shows charge voltage recovery after full discharge. All profiles are taken at $\mathrm{C} / 5$ and polarization over-potentials (right axis) are measured during the first $10 \mathrm{~s}$ of the current pulse after a $2 \mathrm{hr}$ OCV period when switching between charge and discharge at a particular cutoff voltage.

cationic redox. These two properties are now quantified individually in the following section using EIS, GITT and PITT.

Electrochemical impedance spectroscopy (EIS).--For this experiment, a Li / LRSO coin cell is first activated by carrying out five $\mathrm{CCCV}$ cycles, then the cycled electrode is recovered in the discharged state and transferred to a fresh three-electrode Swagelok cell having Li metal at both the counter and reference electrodes. By using two different cells, EIS spectra are measured separately on the charge and discharge paths with varying levels of SOC. More specifically, a GITT procedure with OCV periods of 4 hours (Figures 7a and 7e) is used to reach the desired SOCs before measuring EIS spectra. Features of the spectra are interpreted and modeled similar to the pristine material (First part of Results section) and for sake of conciseness, only three representative spectra, covering the low, middle, and high SOCs, each for charge and discharge paths, are reported and discussed next. The remaining spectra can be found in Supp. Info. Fig. S7.
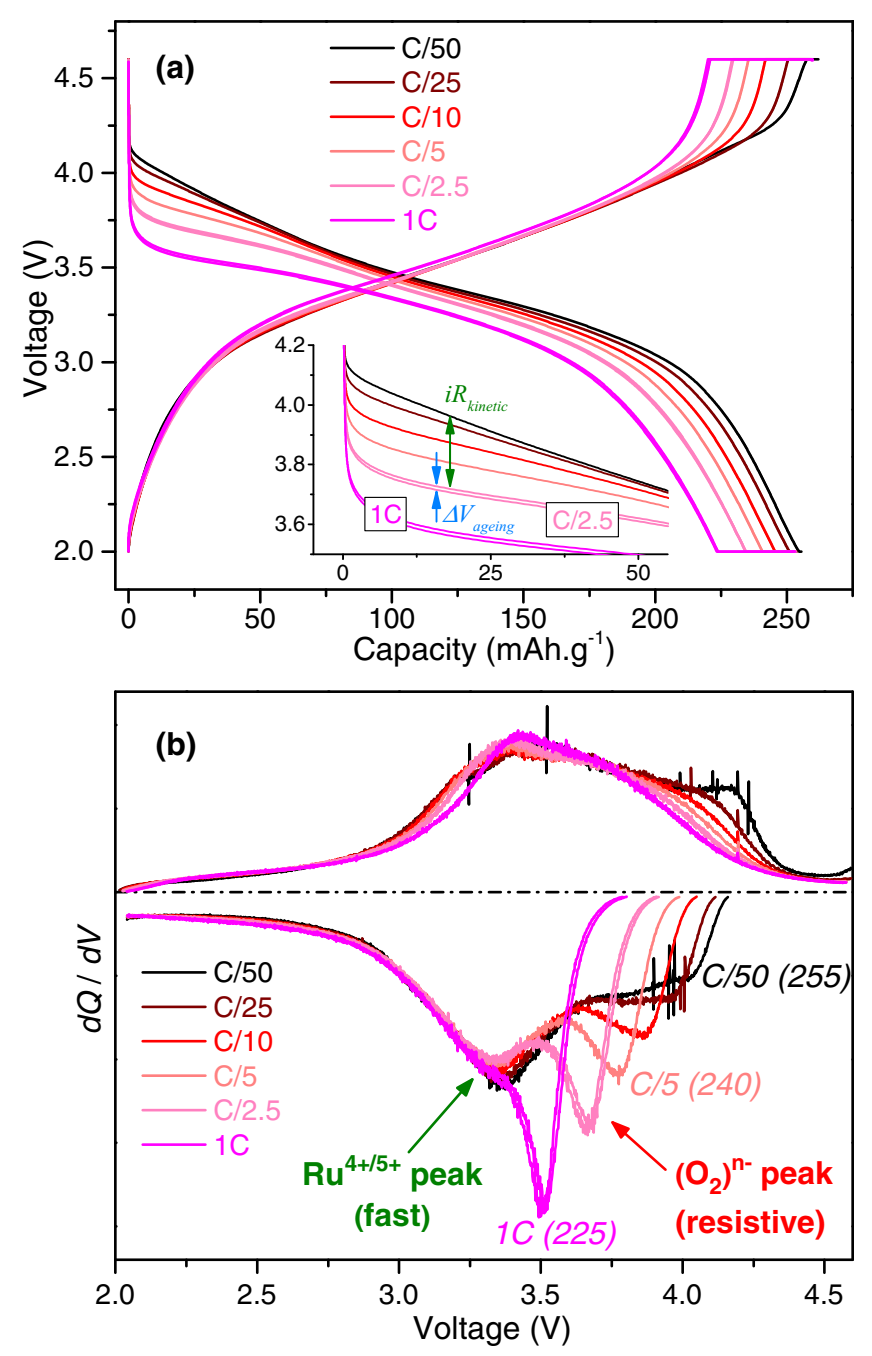

Figure 6. Rata capability of 'activated'-LRSO from C/50 to $1 \mathrm{C}$, measured with $\mathrm{CCCV}$ protocols that ensure identical starting and ending states for each C-rate measurement, i.e. between fully charged to $4.6 \mathrm{~V}$ and fully discharged to $2.0 \mathrm{~V}$. (a) Voltage profiles that are also magnified in the inset to show negligible effect of ageing, $\Delta V_{\text {ageing }} \ll i R_{\text {kinetic }}$. (b) Corresponding $d Q / d V$ profiles showing large polarizations for the oxygen reduction peak. The parentheses show total discharge capacity in $\mathrm{mAh}^{-g^{-1}}$ before reaching $2 \mathrm{~V}$.

In the beginning of charge (Figure 7b), the EIS Nyquist plots show a small $\mathrm{HF}$ arc related to fast electrochemical processes, which in fact stays relatively constant in size throughout the whole charging process (Supplementary Figure S7). Moreover, there is the onset of a very small arc in the MF region related to interfacial charge-transfer resistance that can be seen but very faintly since it is severely overshadowed by the LF Warburg-like feature representing Li diffusion. Next, at mid-SOC (Figure 7c), the $R_{c t}$ arc in MF becomes large enough to be clearly distinguishable visually although its magnitude is still quite small (comparable to the HF resistance), which indicates fast charge-transfer kinetics overall. However, from then onwards, charging further causes a rapid enlargement of the semicircle related to $R_{c t}$. Near the end of charge (Figure 7d), the MF arc becomes very large, thus marking a clear evidence of poor interfacial kinetics for anionic redox. The trends for variations of $R_{c t}$ and $D / R^{2}$ vs. SOC (Figure 7a) are deduced by fitting using the aforementioned equivalent circuit model (Figure 2b-top). $R_{c t}$ (right axis) stays small for the first half of charging but afterwards it grows exponentially by 2 orders of magnitude from mid charge to full charge and toward the end, the spectra move closer to a fully blocking capacitor. In comparison to pristine LRSO (discussed in First part of Results section), Li diffusion 


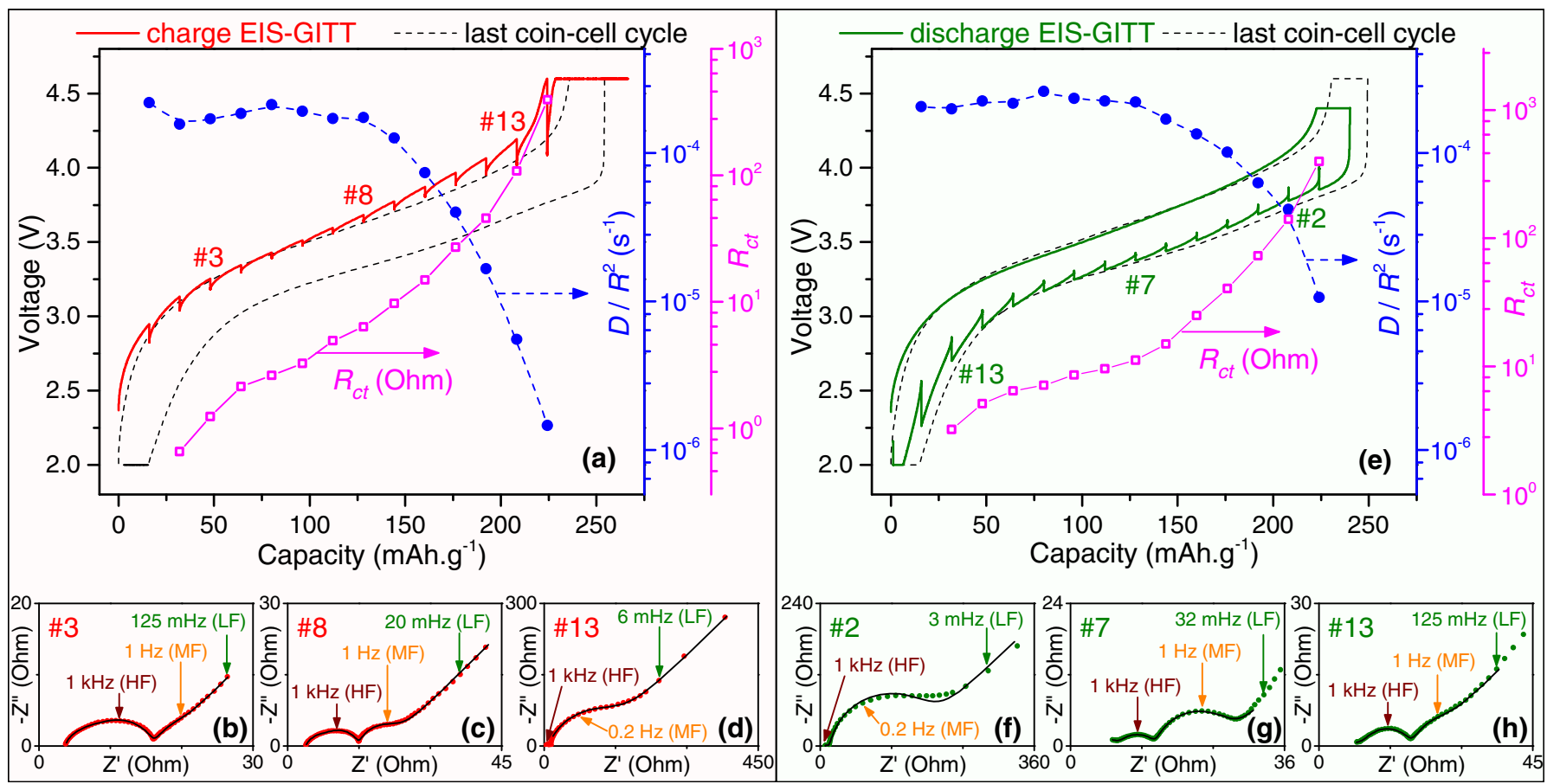

Figure 7. Impedance results for 'activated'-LRSO. EIS - GITT profiles ( $30 \mathrm{~min}$ pulse at C/5, $4 \mathrm{hr}$. rest) for (a) charge and (e) discharge in 3-electrode cells are reproducible and match well with last formation cycles in respective coin-cells. Variation of $D / R^{2}$ and $R_{c t}$ is shown with the right side axes. Measured and simulated Nyquist spectra on charge are shown for points \#3 - slightly-charged in (b), \#8 - mid-charged in (c), and \#13 - nearly-charged in (d). Similarly, for discharge points \#2 - slightly-discharged in (f), \#7 - mid-discharged in (g), and \#13 - nearly-discharged in (h).

is much faster after the activation cycles with $D / R^{2}$ reaching a higher value of $2 \times 10^{-4} \mathrm{~s}^{-1}$. $D / R^{2}$ hovers around this value for the first half of charging and then exponentially deteriorates by 2 orders of magnitude while crossing through the anionic redox regime. We do not however observe a correlation between $D / R^{2}$ and $d Q / d V$ trends, unlike for the pristine material (Fig. 2d), highlighting that 'activated'-LRSO deviates from a purely intercalation-type mechanism.

An identical EIS experiment performed during discharge on a different cell yields similar results which are shown in Figure 7e. Again, three representative EIS Nyquist spectra are shown in Figures $7 \mathrm{f}, 7 \mathrm{~g}$, and $7 \mathrm{~h}$, respectively, for slightly-discharged, mid-discharged, and deeply-discharged states, which are fitted satisfactory according to the equivalent circuit model. Reverse trends are seen for $R_{c t}$ and $D / R^{2}$ on discharge such that both of these properties improve significantly as the anionic redox is discharged, while remaining essentially constant afterwards during cationic discharge. The variations in the HF arc (Supplementary Figure S7) are nowhere as drastic as the MF arc and it remains at a fairly constant and small value, thereby not governing the kinetic properties.

GITT and PITT.-To confirm the limitations spotted by EIS, we tested 'activated'-LRSO electrodes with two additional electrochemical titration techniques, namely GITT and PITT. Figure 8a shows the GITT voltage profiles on charge and discharge and a clear hysteresis is again fully confirmed despite rather long OCV periods of 10 hours. $D / R^{2}$ values, as deduced by following earlier protocol, hardly vary in the first half of charge before encountering anionic redox that initiates a sharp fall in $D / R^{2}$ by 2 orders of magnitude from around $10^{-4}$ to $10^{-6} \mathrm{~s}^{-1}$. The diffusion coefficient recovers back during the initial half of discharge to become flat again in the cationic redox region. PITT profiles (Figure 8b) also show hysteresis even after allowing the currents to decay to an extremely small value of $\mathrm{C} / 500$ before launching the next voltage steps. Current responses at short times after the voltage steps are fitted satisfactorily (Supp. Info. Fig. S8) with a simplified spherical single-particle model described by two parameters,

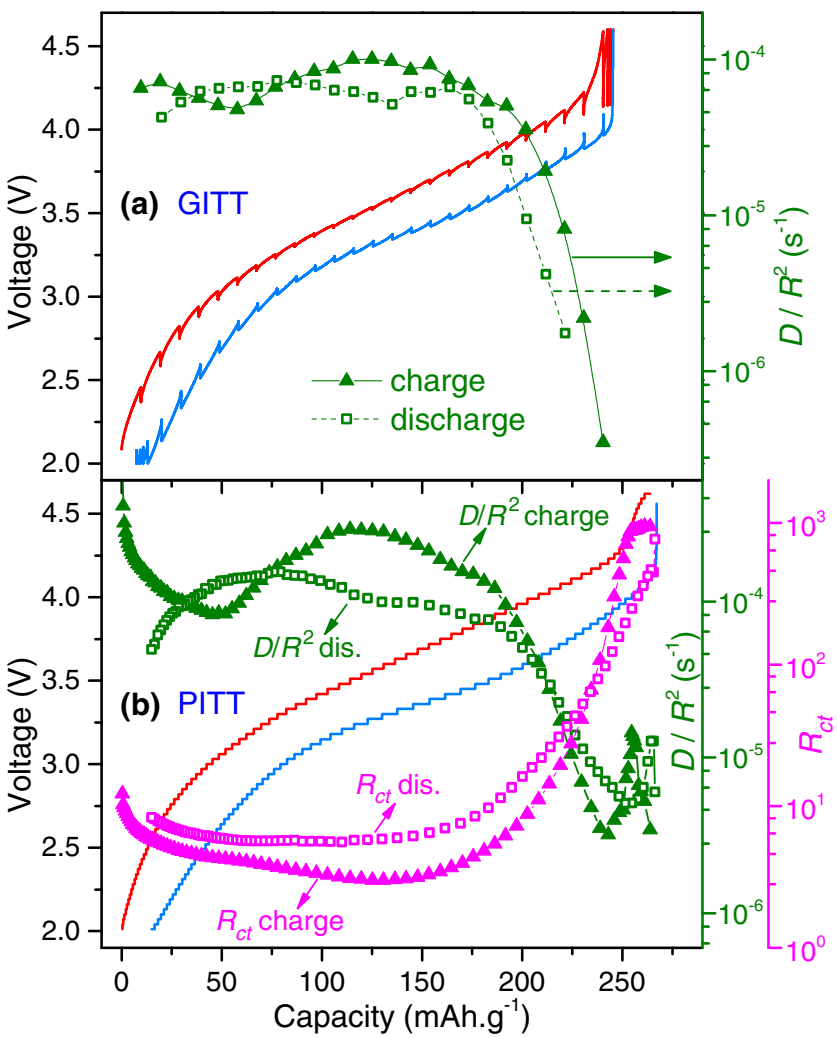

Figure 8. GITT and PITT results for 'activated'-LRSO. (a) Voltage profiles with GITT (C/25 $90 \mathrm{~min}$ pulse, $10 \mathrm{hr}$. rest, $\left.25^{\circ} \mathrm{C}\right)$ and diffusion time constants (right axis). (b) PITT voltage profile $\left(30 \mathrm{mV}\right.$ step, C/500 cutoff, $\left.25^{\circ} \mathrm{C}\right)$ with $D / R^{2}$ and $R_{c t}$ (right axes). Both PITT and GITT show voltage hysteresis. 

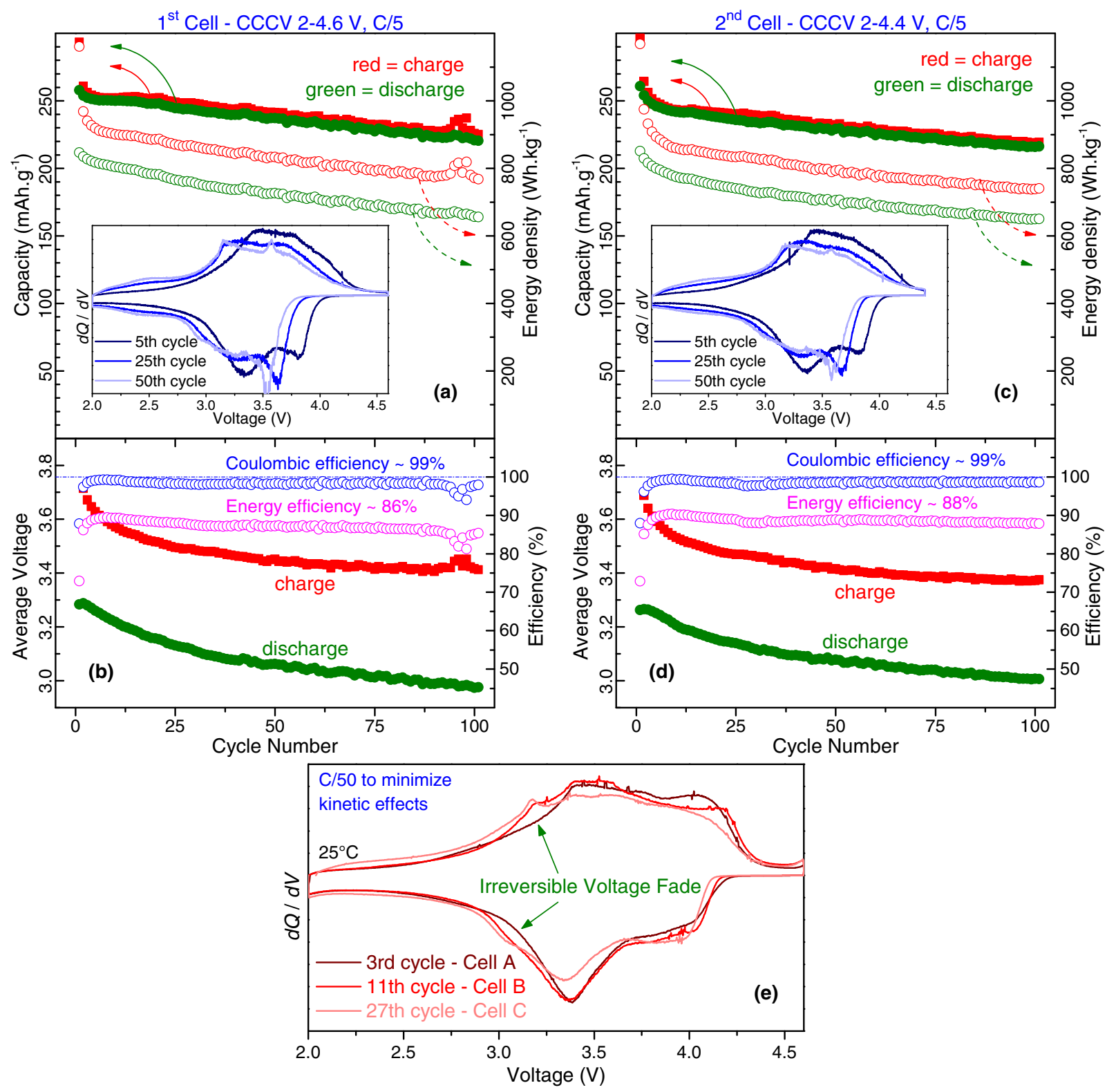

Figure 9. Key performance parameters of 'activated'-LRSO vs. cycle number during long-term ageing ( 100 cycles) with CCCV protocols within 2-4.6 V (panels $\mathrm{a}, \mathrm{b}$ ) and a slightly less harsh 2-4.4 V (panels $\mathrm{c}, \mathrm{d}$ ). Insets show the evolution of the corresponding $d Q / d V$ profiles. Average voltages are calculated by dividing the energy density by specific capacity. (e) $d Q / d V$ profiles at low current ( $\mathrm{CCCV} \mathrm{C/50)}$ for 3 cells having different ages show new redox peaks at $\sim 3.1 \mathrm{~V}$ that appear upon ageing.

namely interfacial charge-transfer and bulk diffusion. From Figure 8 b, both $D / R^{2}$ and $R_{c t}$ can be again seen to deteriorate at higher SOCs that are linked with anionic redox. In summary, using complementary electroanalytical techniques, we have identified a robust correlation of anionic redox with poor interface kinetics and bulk transport properties.

Cycling - voltage fade and impedance buildup.-By carefully designing LRSO with large $\mathrm{Sn}^{4+}$ ions, we had mitigated voltage fade considerably but it was not fully eliminated, motivating us to pursue it further in this study. ${ }^{28}$ Now, we investigate the ageing of LRSO upon long-term cycling, focusing particularly on irreversible voltage fade and impedance buildup. Cycling data for LRSO in two cells over 100 cycles shows how the energy density gradually fades due to a combination of capacity loss (Figs. 9a,9c) as well as decaying average voltage (Figs. 9b,9d), which are plotted as a function of the cycle number. The coulombic efficiency is close to $100 \%$, which proves that side reactions are at minimum, and therefore the low energy efficiency of $86-88 \%$ is a direct consequence of voltage polarization resulting significantly from hysteresis. We note however that the overall performance is not bad given that the material and electrode design was not at all optimized for long-term cycling. A continuous evolution of $d Q / d V$ profiles (Figs. 9a,9c - insets) reveals the trends of shrinking capacities at higher potentials with a simultaneous growth in capacity at lower potentials, explaining the net decay of average charge and discharge voltages. The very broad $d Q / d V$ peak at lower potentials of 2-2.8 V keeps growing upon ageing for both charge and discharge and additionally, a sharp peak is also seen to appear at $3.1 \mathrm{~V}$. This irreversible growth of a sharp charge-discharge peak at $3.1 \mathrm{~V}$ is much clearer from the $d Q / d V$ profiles taken at $3^{\text {rd }}, 11^{\text {th }}$ and $27^{\text {th }}$ cycles in three cells operated at a very low current of C/50 (Fig. 9e) in order to eliminate kinetic effects. Later on, after 50 cycles (Figs. 9a,9c insets), another sharp peak at $3.5 \mathrm{~V}$ can also be seen on charge. Overall, the growth of sharp and broad $d Q / d V$ peaks at different potentials 

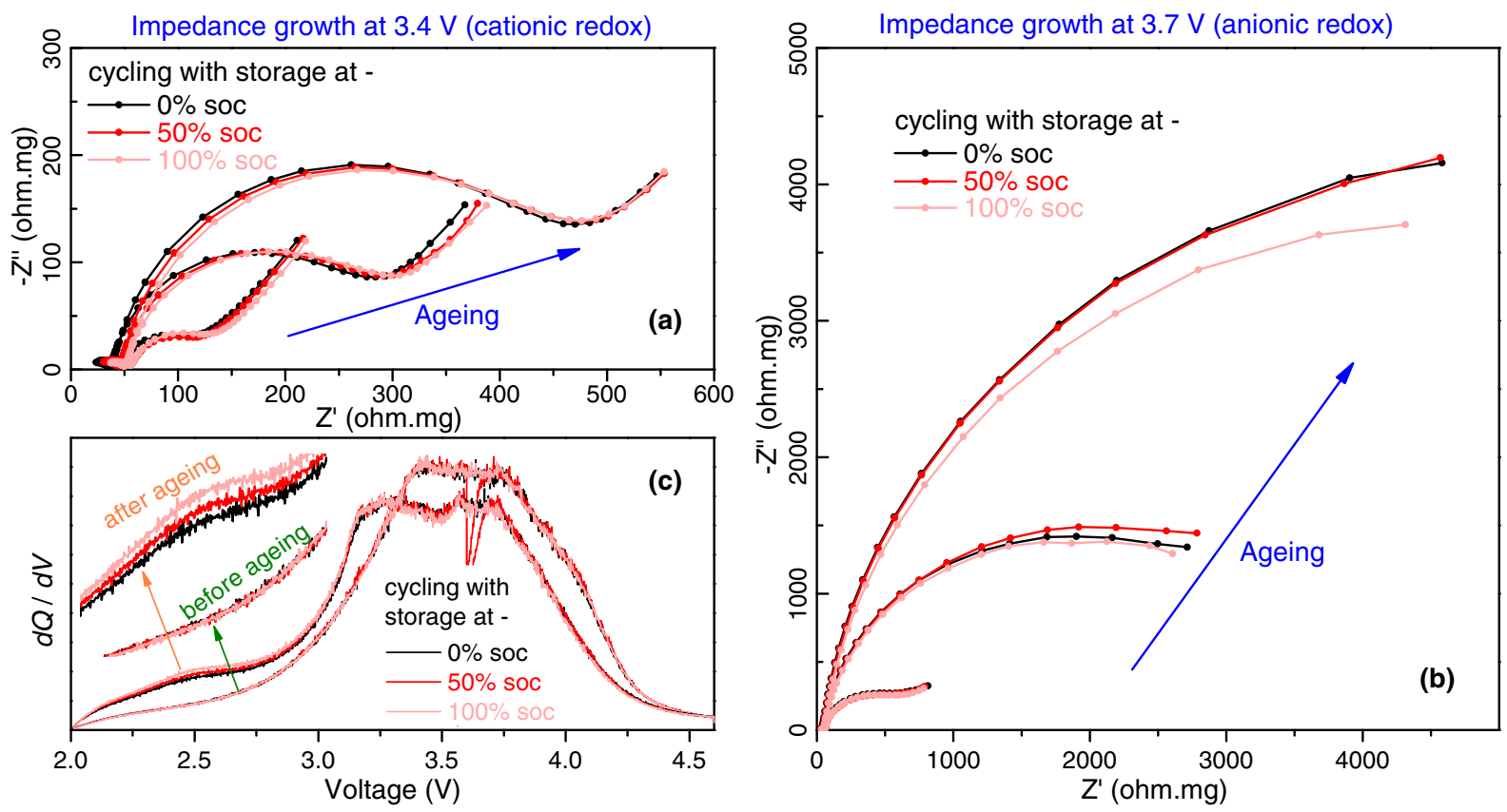

Figure 10. Impedance buildup and voltage fade in a controlled ageing experiment of cycling three 'activated'-LRSO cells with intermediate $24 \mathrm{hr}$. storage periods, respectively at $0 \%, 50 \%$, and $100 \%$ SOC. (a) EIS spectra at $3.4 \mathrm{~V}$ (cationic redox) and (b) $3.7 \mathrm{~V}$ (anionic redox) show growth in $R_{c t}$ (MF arc) but at a much faster rate for the latter. Active material loading is $\sim 5 \mathrm{mg} . \mathrm{cm}^{-2}$. There is no clear trend in terms of impedance among the three cells and minor variations between them are most likely because of uncertainty in AC measurements, especially for large impedance values at $3.7 \mathrm{~V}$. Therefore, their subtle differences are better distinguished with a more precise DC measurement, i.e. $d Q / d V$ in panel (c). Voltage fade around the broad $2.5 \mathrm{~V}$ hump (inset-zoom) is the most severe for the cell with storage at full charge.

highlights the complicated nature of voltage fade in LRSO since it may be related to different types of irreversible mechanisms such as permanent TM migrations or local crystallization of new phases, the exploration of which is beyond the scope of this work. Apart from voltage fade, impedance also builds up upon cycling due to worsening kinetics as evident from the $d Q / d V$ profiles that show a continuous drop in voltage at the very onset of discharge (Figs. 9a,9c - insets).

Next, voltage fade and impedance growth in LRSO are examined through a controlled ageing and check-up experiment, the exact protocol details of which are provided in Supp. Info. Fig S9. In short, three identical 'activated'-LRSO half cells were aged simultaneously by galvanostatic cycling (CCCV at $\mathrm{C} / 5,2.0-4.6 \mathrm{~V}, 2$ cycles) accompanied with an intermediate storage (or $24 \mathrm{hr}$. OCV period) at distinct SOCs for the three cells, i.e. respectively, fully-discharged (0\% SOC), half-charged (50\% SOC), and fully-charged (100\% SOC). EIS spectra are acquired during discharge one by one at $3.4 \mathrm{~V}$ (Figure 10a) and $3.7 \mathrm{~V}$ (Figure 10b), corresponding respectively to cationic and anionic redox processes. In all spectra, there is a small HF depressed semicircle, a larger MF arc, and a LF Warburg tail, which make these full cell spectra very similar to 3-electrode measurements described previously, highlighting minor impedance contributions from the $\mathrm{Li}$ counter electrode. Also, we can again see a much larger MF arc at $3.7 \mathrm{~V}$ compared to $3.4 \mathrm{~V}$ confirming poorer interfacial kinetics for anionic redox. Initially before ageing, EIS spectra neatly superimpose for the three cells at both potentials to demonstrate excellent reproducibility. As the cells age with cycling, the MF arc progressively grows at both potentials, however with a much faster rate at $3.7 \mathrm{~V}$ (Fig. 10b) becoming severely blocking toward the end of the experiment. Thus, impedance builds up much more aggressively at anionic redox explaining the aforementioned increasingly larger over-potentials in the beginning of discharge (Figs. 9a,9c - insets). Because the three cells age in a similar fashion, it shows that impedance growth in LRSO is essentially because of cycling and the SOC at which the cells are rested does not play a significant role in impedance. From Figure $10 \mathrm{c}$, we can also compare the $d Q / d V$ profiles on charge for the three cells such that they perfectly superimpose in the beginning when the three cells are identical. After ageing however, voltage fades $(d Q / d V$ growth around $2.5 \mathrm{~V}$ as deduced by a zoom of the data in Fig. 10cinset) slightly more for the cell that is rested intermittently at $100 \%$ SOC while the cell rested at $0 \%$ SOC fades the least in voltage. A weak correlation is hence concluded between storage SOC and irreversible voltage fade, i.e. spending more time at higher potentials with oxygen in the oxidized state makes LRSO more susceptible to larger irreversible changes and thereby permanent voltage fade. Conversely, when activated LRSO is cycled only till 3.9 V (Supp. Info., Fig. S10), thereby without triggering anionic redox, voltage does not fade at all and the discharge capacity and energy density are also very stable (Supp. Info., Fig. S10). These results agree with that of LR-NMC which also shows faster voltage fade only when cycled at higher potentials. ${ }^{46-48}$ In summary, anionic redox to a certain extent promotes voltage fade and suffers from rapid impedance buildup upon cycling.

\section{Discussion}

By applying detailed electroanalytical techniques to LRSO, which is a 'model' Li-rich layered oxide owing to its structural and electrochemical similarities with LR-NMC, the roles of cationic and anionic redox processes are clarified. LRSO, just like LR-NMC, undergoes a first-cycle activation during which the staircase oxidation profile converts to an 'S-shaped' reduction curve. When oxidation is limited only to the first staircase step (cationic redox), LRSO shows complete reversibility without hysteresis or voltage fade, identical to the previously reported GITT and cycling results on LR-NMC prior to its $4.5 \mathrm{~V}$ plateau, indicating a classical intercalation reaction for both materials. ${ }^{48-50}$ Further oxidation beyond this triggers an anionic redox plateau associated to the generation of $\left(\mathrm{O}_{2}\right)^{\mathrm{n}-}$ species that can reduce back on discharge; however, it is at the expense of a thermodynamic irreversibility because the path taken on discharge (' $S$ '-shaped) is different from that on charge (staircase). Thus, LRSO's $4.15 \mathrm{~V}$ plateau can be viewed as an electrochemically induced, irreversible transformation (or 'activation') at a constant potential in agreement with 
previous measurements (XRD and TEM) that suggested the nucleation of a distorted/disordered phase having permanent local structural changes due to oxygen network distortion (supported by DFT) and TM migration, so that a full discharge can never reset the pristine state. ${ }^{4,28}$ We could however only spot a few local structural differences between pristine vs. materials that were charged and discharged for one cycle, primarily because these two appear very similar and characterization techniques we implemented cannot pinpoint subtle structural motions of either $\mathrm{O}$ or Li atoms. Therefore, further efforts are encouraged for a deeper understanding of structural changes arising during the 'activation' plateau that governs the electrochemistry of LRSO and LR-NMC.

Another specific aspect of these LRSO materials is highlighted from the difficulty to measure the OCV at its flat $4.15 \mathrm{~V}$ 'activation' plateau as we observe a seemingly never-ending equilibration even though the kinetic over-potential is quite small. This observation points to an analogy with conversion-type battery materials that display a similar initial flat plateau with low kinetic over-potential and for which the OCV also drifts for long periods (days to weeks) and departs substantially from the quasi-static potential traces at low currents or under PITT. ${ }^{20,51,52}$ 'Activation' in conversion materials is explained by an irreversible transformation of micro-sized starting particles into a nano-composite which interestingly afterwards cycles according to a rather sloped potential profile. ${ }^{18,20}$ Conversion materials typically show stable voltage profiles once the 'micro to nano activation' is finished, in contrast with Li-rich materials which show continuous voltage fade with cycling. The key difference in Li-rich materials is that their activation plateau is associated with anionic redox and in fact, such a plateau may be an early indication of structural instability of oxidized oxygen because it leads to reorganization. Such anionic redox driven transformations may continue beyond the $1^{\text {st }}$ cycle, perhaps more slowly (and hence voltage fade). Therefore, one possible strategy is to design Li-rich materials that do not display a $1^{\text {st }}$ cycle activation plateau. Whether fortuitous or not, the similarity between Li-rich LRSO and conversion materials deserves greater attention on a fundamental basis.

Once the Li-rich layered oxide is activated, we have spotted another practical issue, i.e. voltage hysteresis that ranges from 150-250 $\mathrm{mV}$ in LRSO, which makes SOC management cumbersome. Also, such a potential hysteresis, which is nearly zero in conventional intercalation materials, such as NMC and NCA, contributes to lowering the round trip energy efficiency of LRSO to around 86 to $88 \%$ (Fig. 9) and likewise for LR-NMC (Supp. Info. Fig S11). This energy loss in each cycle is dissipated as heat and calls for additional thermal management to keep such batteries safe during operation. We agree with previous hypotheses that such a voltage hysteresis has structural origins since it is supported by Nuclear Magnetic Resonance (NMR) experiments from which different pathways between charge and discharge were identified on the second cycle for $\mathrm{LRSO}^{53}$ and also for 'activated'-LR-NMC ${ }^{54}$ after several cycles. Moving beyond this initial understanding, we have now fundamentally answered whether such a structural hysteresis originates from anionic redox, a question that was legitimized by previous studies that blamed oxidation at high potentials around $4.5 \mathrm{~V}$ (and hence oxygen redox) for hysteresis in LR-NMC. ${ }^{49,50,55,56}$

Answering this question was difficult with LR-NMC because its charge compensation from cations and anions is highly convoluted, and therefore we could only succeed with 'activated' LRSO (i.e. after a full first cycle) by showing that it offers the unique ability to unambiguously decouple the effects of cationic and anionic redox that are sufficiently well separated at low and high potentials, respectively. By leveraging this ability here, we demonstrate a clear correlation between anionic redox and hysteresis by simply probing the effect of cutoff voltages. Hysteresis begins only after triggering anionic redox and afterwards, it grows continuously as more $\mathrm{O}^{2-}$ anions in LRSO are oxidized at higher potential. On the other hand, cycling only till $3.9 \mathrm{~V}$ and hence not triggering anionic redox-driven hysteresis, leads to much higher energy efficiencies of $95 \%$ (Supp. Info. Fig. S10). At this stage, one must recall that the triggering of anionic redox is accompanied by a massive TM migration which partially reverts back on discharge, as deduced from TEM studies, ${ }^{28}$ when the anionic species are reduced. Fortunately, DFT fully supported this mechanism even though TEM could not directly monitor the formation of anionic O-O species owing to structural symmetry incompatibilities associated to LRSO's O3-type arrangement. Regardless, oxidation/reduction causes formation/dissociation of $\mathrm{O}-\mathrm{O}$ dimers leading to structural changes, a process that would require a threshold energy and therefore we believe that this is what is responsible for the voltage hysteresis, quite similar again to conversion reactions where there is also a repeated breaking and creating of bonds. At the same time, the possibility of a non-monotonic equilibrium potential, that neatly explained hysteresis in $\mathrm{LiFePO}_{4}$, cannot be excluded. ${ }^{57,58}$ Although the magnitude of hysteresis in LRSO (150-250 mV at C/50) is much lesser compared to LR-NMC's $400-500 \mathrm{mV}$ at C/300 ${ }^{59}$ and $\sim 500 \mathrm{mV}$ at C/5 (Supp. Info. Fig S11), it is perhaps an inherent feature of such Li-rich layered oxides with varying degrees of severity depending on chemical compositions. Therefore, from a material-design perspective, completely avoiding hysteresis in the presence of anionic redox calls for designing more robust crystal structures. One fully $3 \mathrm{D}$ structure bearing cumulative cationic and anionic processes is presently being investigated in our group with very promising results that will be reported elsewhere.

Kinetics is also another important figure of merit regarding practical applications as it is necessary for high power density and good energy efficiency, both of which enable better thermal safety. The connection of anionic redox with poor kinetics was first spotted in LRSO with Electron Paramagnetic Resonance Imaging (EPRI) ${ }^{29}$ and now we are confident that this connection is robust as deduced by complementary EIS, GITT, and PITT, which show that that $D / R^{2}$ and $R_{c t}$ for 'activated'-LRSO deteriorate by two orders of magnitude leading to fast impedance rise when triggering anionic redox. Such a negative effect of anionic redox on kinetics can also be spotted in other Li-rich layered oxides, for example in $\mathrm{Li}_{2} \mathrm{RuO}_{3}$ 's non-explored GITT data ${ }^{60}$ and from LR-NMC's rate-capability data, ${ }^{25}$ both showing larger over-potentials in the beginning of discharge. We hypothesize that kinetics may improve for materials in which anionic redox does not necessitate severe structural rearrangements, such as either drastic O-O dimerization or TM migrations. Within this context, $\mathrm{Li}_{2} \mathrm{IrO}_{3}$ whose redox process enlists the formation of $\mathrm{O}-\mathrm{O}$ dimers but without TM migration is being presently tested with the same protocols and results will be reported in an upcoming paper.

The last major practical issue in LR-NMC, and undoubtedly the most studied, is voltage fade because it gradually diminishes the cell's energy output (Supp. Info. Fig. S11) and the continuously evolving voltage profiles make it hard from a battery management perspective. Herein, we unambiguously show that anionic redox is at the heart of the voltage fade and impedance buildup but the exact mechanisms by which this takes place remain unexplored. It could either arise from the capturing of some TM ions in tetrahedral sites during the back and forth cationic migrations upon cycling as previously reported ${ }^{28}$ or via some irreversible modification of the oxygen lattice. This keeps the avenue open for different chemical strategies (for both surface and bulk) to mitigate voltage fade. ${ }^{61}$ Among them is the use of chemical substituents less prone to be captured in tetrahedral sites (such as $\mathrm{Sn}^{+4}$ ), as we previously reported, ${ }^{28}$ or the direct chemical tuning of the oxygen surface, as recently shown for LR-NMC. ${ }^{62}$ Neither of these is at this stage a perfect way around and further materials design strategies need to be explored.

Lastly, our data support that voltage fade and hysteresis are correlated (because both are aggravated by anionic redox at higher potentials) as previously suggested for LR-NMC. ${ }^{63}$ An attempt to model successfully the large hysteresis in LR-MNC with an electrochemical model, assuming back and forth conversions of $\mathrm{Li}_{2} \mathrm{MnO}_{3}$ 'domains' during charge and discharge, was previously published. ${ }^{59}$ We are currently implementing a similar model for LRSO aided by better understanding gained from this study about the different roles of cationic and anionic redox. Cycling induced voltage fade and resistance buildup, respectively, are thermodynamic and kinetic 
phenomena that take place together in LRSO and quantifying their individual contributions to performance decay calls for the development of electrochemical and phenomenological models, similar to those recently implemented for LR-NMC. ${ }^{59,64}$

\section{Conclusions}

In summary, our detailed electrochemical investigations have not only revealed remarkable similarities between the two Li-rich layered oxides, i.e. LR-NMC (a practical cathode) and LRSO (a model cathode), but more importantly pointed out that anionic redox is initiating key practical problems that obstruct commercialization. The staggering increase in capacity brought by anionic redox in Li-rich layered materials comes at a price, i.e. it simultaneously triggers hysteresis, promotes voltage fade, and builds up impedance upon cycling. It now becomes clear that kinetically-wise anionic redox process is more sluggish than the cationic one. Several extensions of the present work, besides mitigating the detrimental side effects via tuning material structural/chemical stability through substitution or surface grafting, are immediately apparent. They range from extending these studies to other Li-rich layered oxide phases showing anionic redox activity, either without $(\mathrm{O}-\mathrm{O})$ pairs or with it but avoiding TM migration, to the elaboration of electrochemical and phenomenological models that can fully rationalize our experimental findings. Our results should warn researchers to also keep in mind practical applications in the pursuit of anionic redox which is gaining fast importance in electrochemical systems, ${ }^{65}$ including Na-based cathodes ${ }^{66-68}$ and cation-disordered cathodes. ${ }^{69}$ Solving these issues is not insurmountable and we hope that our timely identification of these fundamental bottlenecks toward real-world applications will encourage direct targeting of anionic redox with fundamental studies and mitigation strategies for neutralizing the problems with LR-NMC materials in general and facilitating its utilization in practical high energy density Li-ion batteries.

\section{Acknowledgments}

We are thankful to K. Ramesha for preparing some of the studied samples. J.-M.T. acknowledges funding from the European Research Council (ERC) (FP/2014-2020)/ERC Grant-Project 670116ARPEMA.

\section{References}

1. J. B. Goodenough and K.-S. Park, J. Am. Chem. Soc., 135, 1167 (2013)

2. L. Croguennec and M. R. Palacin, J. Am. Chem. Soc., 137, 3140 (2015).

3. J. M. Tarascon, G. Vaughan, Y. Chabre, L. Seguin, M. Anne, P. Strobel, and G. Amatucci, J. Solid State Chem., 147, 410 (1999).

4. M. Sathiya, G. Rousse, K. Ramesha, C. P. Laisa, H. Vezin, M. T. Sougrati, M.-L. Doublet, D. Foix, D. Gonbeau, W. Walker, A. S. Prakash, M. Ben Hassine, L. DuPont, and J.-M. Tarascon, Nat. Mater., 12, 827 (2013).

5. P. Rozier and J. M. Tarascon, J. Electrochem. Soc., 162, A2490 (2015)

6. E. McCalla, A. M. Abakumov, M. Saubanère, D. Foix, E. J. Berg, G. Rousse, M.-L. Doublet, D. Gonbeau, P. Novák, G. V. Tendeloo, R. Dominko, and J.-M. Tarascon, Science, 350, 1516 (2015).

7. M. Saubanère, E. McCalla, J.-M. Tarascon, and M.-L. Doublet, Energy Env. Sci, 9 984 (2016).

8. T. Ohzuku, M. Nagayama, K. Tsuji, and K. Ariyoshi, J. Mater. Chem., 21, 10179 (2011).

9. D.-H. Seo, J. Lee, A. Urban, R. Malik, S. Kang, and G. Ceder, Nat. Chem., 8, 692 (2016).

10. M. Oishi, C. Yogi, I. Watanabe, T. Ohta, Y. Orikasa, Y. Uchimoto, and Z. Ogumi, $J$ Power Sources, 276, 89 (2015).

11. K. Luo, M. R. Roberts, R. Hao, N. Guerrini, D. M. Pickup, Y.-S. Liu, K. Edström, J. Guo, A. V. Chadwick, L. C. Duda, and P. G. Bruce, Nat. Chem., 8, 684 (2016).

12. K. Shimoda, T. Minato, K. Nakanishi, H. Komatsu, T. Matsunaga, H. Tanida, H. Arai, Y. Ukyo, Y. Uchimoto, and Z. Ogumi, J Mater Chem A, 4, 5909 (2016).

13. D. Foix, M. Sathiya, E. McCalla, J.-M. Tarascon, and D. Gonbeau, J. Phys. Chem. $C, \mathbf{1 2 0}, 862$ (2016)

14. J. Hong, H. Gwon, S.-K. Jung, K. Ku, and K. Kang, J. Electrochem. Soc., 162, A2447 (2015).

15. S. Hy, H. Liu, M. Zhang, D. Qian, B.-J. Hwang, and Y. S. Meng, Energy Environ Sci., 9, 1931 (2016)

16. A. Manthiram, J. C. Knight, S.-T. Myung, S.-M. Oh, and Y.-K. Sun, Adv. Energy Mater, 6, 1501010 (2016)

17. P. Meister, H. Jia, J. Li, R. Klöpsch, M. Winter, and T. Placke, Chem. Mater. (2016)
18. R. Khatib, A.-L. Dalverny, M. Saubanère, M. Gaberscek, and M-L. Doublet, J. Phys. Chem. C, 117, 837 (2013).

19. H.-C. Yu, C. Ling, J. Bhattacharya, J. C. Thomas, K. Thornton, and A. Van der Ven, Energy Environ. Sci., 7, 1760 (2014).

20. A. Ponrouch, J. Cabana, R. Dugas, J. L. Slack, and M. R. Palacín, RSC Adv., 4, 35988 (2014).

21. L. Li, R. Jacobs, P. Gao, L. Gan, F. Wang, D. Morgan, and S. Jin, J. Am. Chem. Soc, 138, 2838 (2016).

22. M. Oishi, K. Yamanaka, I. Watanabe, K. Shimoda, T. Matsunaga, H. Arai, Y. Ukyo, Y. Uchimoto, Z. Ogumi, and T. Ohta, J. Mater. Chem. A, 4, 9293 (2016).

23. R. Yuge, A. Toda, S. Kuroshima, H. Sato, T. Miyazaki, N. Tamura, M. Tabuchi, and K. Nakahara, Electrochimica Acta, 189, 166 (2016)

24. X. Yu, Y. Lyu, L. Gu, H. Wu, S.-M. Bak, Y. Zhou, K. Amine, S. N. Ehrlich, H. Li, K.-W. Nam, and X.-Q. Yang, Adv. Energy Mater., 4, 1300950 (2014).

25. J. Zheng, W. Shi, M. Gu, J. Xiao, P. Zuo, C. Wang, and J.-G. Zhang, J. Electrochem Soc., 160, A2212 (2013).

26. J. R. Croy, M. Balasubramanian, K. G. Gallagher, and A. K. Burrell, Acc. Chem. Res., 48, 2813 (2015).

27. M. Sathiya, K. Ramesha, G. Rousse, D. Foix, D. Gonbeau, A. S. Prakash, M. L. Doublet, K. Hemalatha, and J.-M. Tarascon, Chem. Mater., 25, 1121 (2013).

28. M. Sathiya, A. M. Abakumov, D. Foix, G. Rousse, K. Ramesha, M. Saubanère, M. L. Doublet, H. Vezin, C. P. Laisa, A. S. Prakash, D. Gonbeau, G. VanTendeloo, and J.-M. Tarascon, Nat. Mater., 14, 230 (2014).

29. M. Sathiya, J.-B. Leriche, E. Salager, D. Gourier, J.-M. Tarascon, and H. Vezin, Nat Commun., 6, 6276 (2015).

30. J.-M. Tarascon, A. S. Gozdz, C. Schmutz, F. Shokoohi, and P. C. Warren, Solid State Ion., 86, 49 (1996)

31. C. J. Wen, B. A. Boukamp, R. A. Huggins, and W. Weppner, J. Electrochem. Soc., 126, 2258 (1979).

32. M. Guo and R. E. White, J. Power Sources, 198, 322 (2012).

33. J. Li, X. Xiao, F. Yang, M. W. Verbrugge, and Y.-T. Cheng, J. Phys. Chem. C, 116, 1472 (2012)

34. J. Li, F. Yang, X. Xiao, M. W. Verbrugge, and Y.-T. Cheng, Electrochimica Acta, $\mathbf{7 5}$ $56(2012)$

35. C. Ho, I. D. Raistrick, and R. A. Huggins, J. Electrochem. Soc., 127, 343 (1980).

36. M. Doyle, J. P. Meyers, and J. Newman, J. Electrochem. Soc., 147, 99 (2000).

37. M. Gaberscek, J. Moskon, B. Erjavec, R. Dominko, and J. Jamnik, Electrochem. Solid-State Lett., 11, A170 (2008).

38. J.-M. Atebamba, J. Moskon, S. Pejovnik, and M. Gaberscek, J. Electrochem. Soc., 157, A1218 (2010).

39. M. D. Levi and D. Aurbach, J. Phys. Chem. B, 101, 4630 (1997).

40. M. D. Levi and D. Aurbach, J. Phys. Chem. B, 101, 4641 (1997)

41. D. R. Baker and M. W. Verbrugge, J. Electrochem. Soc., 159, A1341 (2012).

42. L. Xiao, Y. Guo, D. Qu, B. Deng, H. Liu, and D. Tang, J. Power Sources, 225, 286 (2013).

43. D. M. Bernardi, R. Chandrasekaran, and J. Y. Go, J. Electrochem. Soc., 160, A1430 (2013).

44. M. Farkhondeh and C. Delacourt, J. Electrochem. Soc., 159, A177 (2012).

45. J. S. Newman and K. E. Thomas-Alyea, Electrochemical systems, 3rd ed., p. 647, J Wiley, Hoboken, N.J, (2004)

46. M. Bettge, Y. Li, K. Gallagher, Y. Zhu, Q. Wu, W. Lu, I. Bloom, and D. P. Abraham, J. Electrochem. Soc., 160, A2046 (2013)

47. J. Yang, L. Xiao, W. He, J. Fan, Z. Chen, X. Ai, H. Yang, and Y. Cao, ACS Appl. Mater. Interfaces, 8, 18867 (2016).

48. Y. Wu, C. Ma, J. Yang, Z. Li, L. F. Allard, C. Liang, and M. Chi, J. Mater. Chem. A, 3, 5385 (2015).

49. J. R. Croy, K. G. Gallagher, M. Balasubramanian, Z. Chen, Y. Ren, D. Kim, S.-H. Kang, D. W. Dees, and M. M. Thackeray, J. Phys. Chem. C, 117, 6525 (2013).

50. M. Kasai, S. Nishimura, A. Gunji, H. Konishi, X. Feng, S. Furutsuki, and S. Takahashi, Electrochimica Acta, 146, 79 (2014).

51. P. L. Taberna, S. Mitra, P. Poizot, P. Simon, and J.-M. Tarascon, Nat. Mater, 5, 567 (2006).

52. J. K. Ko, K. M. Wiaderek, N. Pereira, T. L. Kinnibrugh, J. R. Kim, P. J. Chupas, K. W. Chapman, and G. G. Amatucci, ACS Appl. Mater. Interfaces, 6, 10858 (2014).

53. E. Salager, V. Sarou-Kanian, M. Sathiya, M. Tang, J.-B. Leriche, P. Melin, Z. Wang, H. Vezin, C. Bessada, M. Deschamps, and J.-M. Tarascon, Chem. Mater., 26, 7009 (2014).

54. F. Dogan, B. R. Long, J. R. Croy, K. G. Gallagher, H. Iddir, J. T. Russell, M. Balasubramanian, and B. Key, J. Am. Chem. Soc., 137, 2328 (2015).

55. J. R. Croy, K. G. Gallagher, M. Balasubramanian, B. R. Long, and M. M. Thackeray, J. Electrochem. Soc., 161, A318 (2014).

56. H. Konishi, T. Hirano, D. Takamatsu, A. Gunji, X. Feng, and S. Furutsuki, J. Power Sources, 298, 144 (2015).

57. W. Dreyer, J. Jamnik, C. Guhlke, R. Huth, J. Moškon, and M. Gaberšček, Nat. Mater. 9, 448 (2010)

58. M. Farkhondeh, M. Pritzker, M. Fowler, M. Safari, and C. Delacourt, Phys Chem Chem Phys, 16, 22555 (2014)

59. D. W. Dees, D. P. Abraham, W. Lu, K. G. Gallagher, M. Bettge, and A. N. Jansen, J. Electrochem. Soc., 162, A559 (2015).

60. B. Li, R. Shao, H. Yan, L. An, B. Zhang, H. Wei, J. Ma, D. Xia, and X. Han, Adv. Funct. Mater, 26, 1330 (2016).

61. H. Koga, L. Croguennec, M. Ménétrier, P. Mannessiez, F. Weill, and C. Delmas, J. Power Sources, 236, 250 (2013).

62. B. Qiu, M. Zhang, L. Wu, J. Wang, Y. Xia, D. Qian, H. Liu, S. Hy, Y. Chen, K. An, Y. Zhu, Z. Liu, and Y. S. Meng, Nat. Commun., 7, 12108 (2016). 
63. K. G. Gallagher, J. R. Croy, M. Balasubramanian, M. Bettge, D. P. Abraham, A. K. Burrell, and M. M. Thackeray, Electrochem. Commun., 33, 96 (2013).

64. S. G. Rinaldo, K. G. Gallagher, B. R. Long, J. R. Croy, M. Bettge, D. P. Abraham, J. Bareño, and D. W. Dees, J. Electrochem. Soc., 162, A897 (2015).

65. A. Grimaud, W. T. Hong, Y. Shao-Horn, and J.-M. Tarascon, Nat. Mater, 15, 121 (2016)

66. P. Rozier, M. Sathiya, A.-R. Paulraj, D. Foix, T. Desaunay, P.-L. Taberna, P. Simon, and J.-M. Tarascon, Electrochem. Commun., 53, 29 (2015).
67. B. Mortemard de Boisse, G. Liu, J. Ma, S. Nishimura, S.-C. Chung, H. Kiuchi, Y. Harada, J. Kikkawa, Y. Kobayashi, M. Okubo, and A. Yamada, Nat. Commun., 7, 11397 (2016).

68. A. J. Perez, D. Batuk, M. Saubanère, G. Rousse, D. Foix, E. Mc Calla, E. J. Berg, R. Dugas, K. van den Bos, M.-L. Doublet, D. Gonbeau, A. M. Abakumov, G. V. Tendeloo, and J.-M. Tarascon, Chem. Mater. (2016) .

69. N. Yabuuchi, M. Takeuchi, M. Nakayama, H. Shiiba, M. Ogawa, K. Nakayama, T. Ohta, D. Endo, T. Ozaki, T. Inamasu, K. Sato, and S. Komaba, Proc. Natl. Acad. Sci., 112, 7650 (2015). 